\title{
Next Generation Nuclear Plant Project Evaluation of Siting an HTGR Co-Generation Plant on an Operating Commercial Nuclear Power Plant Site
}

The INL is a

U.S. Department of Energy

National Laboratory

operated by

Battelle Energy Alliance

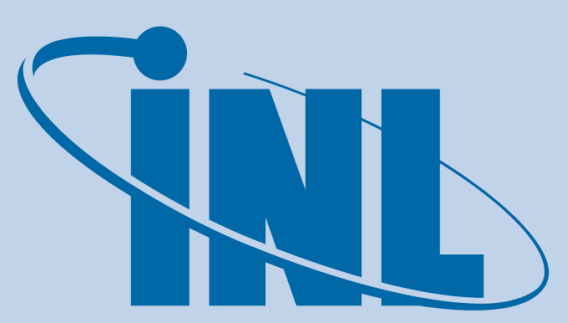

Idaho National Laboratory
October 2011

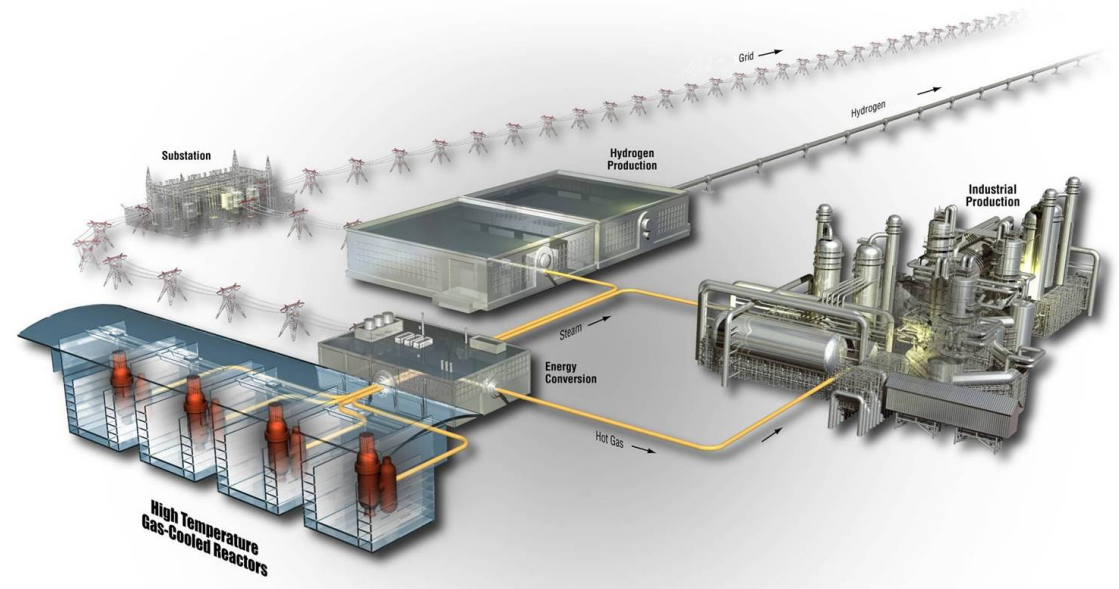




\section{DISCLAIMER}

This information was prepared as an account of work sponsored by an agency of the U.S. Government. Neither the U.S. Government nor any agency thereof, nor any of their employees, makes any warranty, expressed or implied, or assumes any legal liability or responsibility for the accuracy, completeness, or usefulness, of any information, apparatus, product, or process disclosed, or represents that its use would not infringe privately owned rights. References herein to any specific commercial product, process, or service by trade name, trade mark, manufacturer, or otherwise, does not necessarily constitute or imply its endorsement, recommendation, or favoring by the U.S. Government or any agency thereof. The views and opinions of authors expressed herein do not necessarily state or reflect those of the U.S. Government or any agency thereof. 


\section{Next Generation Nuclear Plant Project Evaluation of Siting an HTGR Co-Generation Plant on an Operating Commercial Nuclear Power Plant Site}

October 2011

Idaho National Laboratory Next Generation Nuclear Plant Project Idaho Falls, Idaho 83415

http://www.inl.gov

Prepared for the

U.S. Department of Energy

Office of Nuclear Energy

Under DOE Idaho Operations Office

Contract DE-AC07-05ID14517 

Next Generation Nuclear Plant Project

\section{Next Generation Nuclear Plant Project Evaluation of Siting an HTGR Co-generation Plant on an Operating Commercial Nuclear Power Plant Site}

INL/EXT-11-23282

October 2011

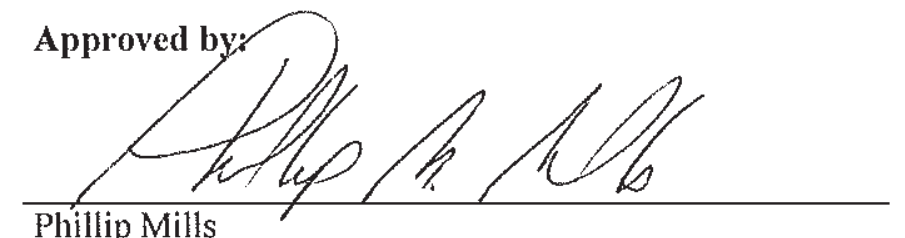

NGNP Project Engineering Director

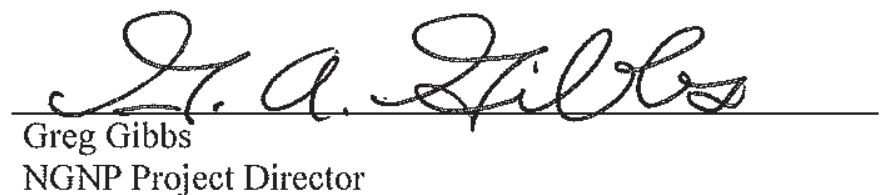

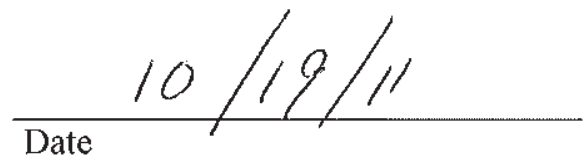

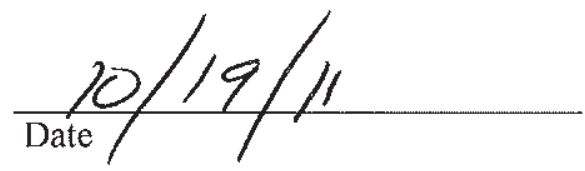





\begin{abstract}
This paper summarizes a scoping evaluation of siting a high temperature gascooled reactor (HTGR) cogeneration plant at the Waterford Steam Electric Station in St. Charles Parish, Louisiana. This hypothetical evaluation was performed by the Idaho National Laboratory Next Generation Nuclear Plant Project. The feasibility of locating the HTGR plant on the Waterford site was evaluated considering the size of the HTGR plant boundaries, expected exclusion area boundary of the plant, ability to construct the plant on the site with emphasis on the nature and depth of required excavations and site preparation, use of water extracted from the Mississippi for turbine generator condenser and other auxiliary cooling needs, availability of water for other plant needs, and ability to receive and transport large vessels and other major components such as turbine generator shells and rotors to the HTGR plant site. This assessment concludes that the Waterford site appears to be viable for siting the HTGR plant.

This evaluation was conducted as part of NGNP Project assessments of the feasibility of siting the HTGR to support different industrial applications under different site conditions. For example, in other similar work, the NGNP Project has evaluated siting the HTGR within or close-by existing petrochemical facilities, and performed scoping analyses for siting a plant in a remote area supplying steam, electricity, and high temperature gas for recovery and upgrading of unconventional crude oil. This evaluation of the Waterford site continues this work by evaluating the viability of siting an HTGR plant on an existing nuclear power plant site. The Waterford nuclear power plant site was selected for this evaluation because it is located in an area of significant industrial activity with potential off-takers of steam and electricity supplied by the HTGR plant.
\end{abstract}




\section{SUMMARY}

This paper summarizes a scoping evaluation of siting a high temperature gas-cooled reactor (HTGR) cogeneration plant at the Waterford Steam Electric Station in St. Charles Parish, Louisiana. ${ }^{a}$ This evaluation was performed by the Idaho National Laboratory (INL) Next Generation Nuclear Plant (NGNP) Project. This site currently includes the Waterford 1 and 2 natural gas, Waterford- 3 nuclear, and Waterford 4 diesel electric generation plants. This evaluation was conducted as part of NGNP Project assessments of the feasibility of siting the HTGR to support different industrial applications under different site conditions. For example, in other similar work, the NGNP Project has evaluated siting the HTGR within or close-by existing petrochemical facilities, and performed scoping analyses for siting a plant in a remote area supplying steam, electricity, and high temperature gas for recovery and upgrading of unconventional crude oil. This evaluation of the Waterford site continues this work by evaluating the viability of siting an HTGR plant on an existing nuclear power plant site. The Waterford nuclear power plant site was selected for this evaluation because it is located in an area of significant industrial activity with potential off-takers of steam and electricity supplied by the HTGR plant.

The feasibility of locating the HTGR plant on the Waterford site was evaluated considering the size of the HTGR plant boundaries, expected exclusion area boundary of the plant, ability to construct the plant on the site with emphasis on the nature and depth of required excavations and site preparation, use of water extracted from the Mississippi for turbine generator condenser and other auxiliary cooling needs, availability of water for other plant needs, and ability to receive and transport to the HTGR plant site large vessels and other major components, (e.g., turbine generator shells and rotors).

The location and energy needs of industrial plants (potential off-takers) close by the selected site were identified and assessed for supply by an HTGR plant. This effort included determining the annual energy consumption of these industrial plants through review of data collected and published by the U.S. Department of Energy/Energy Information Agency. Meetings were also held with The Dow Chemical Company to elicit their interest in considering the HTGR as a long term energy supply and the types and amounts of energy that they require.

Once the energy needs of potential end users was understood, a conceptual HTGR plant design was developed with the capability to meet these energy needs, including forms of energy, reliability and availability. Scoping analyses were performed for this plant design to evaluate the economic viability of this application.

In support of this evaluation, a separate site assessment was performed by NGNP Project Licensing that considered health and safety, environmental and sociological, and other important siting characteristics to determine the potential impact of identified hazards and potential challenges presented by the location for licensing this technology with the U.S. Nuclear Regulatory Commission (NRC).

a. The Waterford station is currently owned by Entergy Louisiana, LLC (ELL) which is a regulated utility. INL conducted its feasibility assessment of the Waterford station based on publicly available information. As this study is merely an effort to determine feasibility of locating a HTGR at an existing commercial nuclear site, as opposed to assessing commercial viability of such a project of Waterford, INL did not attempt to determine whether ELL was interested in locating a HTGR co-generation plant at Waterford station or the terms on which it would be interested. Accordingly, nothing in this report should be construed as ELL's consent to locate such a project at Waterford station or to waive its rights to distribute and sell electricity to customers in the vicinity of Waterford or throughout the 46 parishes in which it provides electric service in Louisiana. While ELL co-operated in this site feasibility study, the views expressed herein are those of INL and not ELL.

This study assumes a business model where an HTGR plant owned by a stand-alone entity would be located at ELL's Waterford station and would sell heat, steam and electricity to nearby industrial concerns and sell excess electricity to regional utilities and others. The generation, transmission, distribution and sale of electricity implicates a number of federal and state laws, rules and regulations. It is beyond the scope of this feasibility study to analyze whether the assumed business model is consistent with or permitted by such laws or whether it improperly infringes on the exclusive rights of area utilities, including ELL, to distribute and sell electricity on the retail market. 
The technical, hazards, and economic evaluations summarized in this report do not identify any conditions that would prevent locating an HTGR cogeneration plant on the Waterford site. For the purposes of this evaluation it was assumed that this plant could supply steam and electricity to the plants located within 1-1/2 miles of the selected HTGR plant site and excess electricity for sale to regional utilities. The plant design selected has a thermal rating of 3,600 MW(t) comprised of six $600 \mathrm{MW}(\mathrm{t})$ HTGR nuclear heat supply systems. The plant can supply up to $\sim 3$ million lb/hour of steam and $500 \mathrm{MW}(\mathrm{e})$ to industrial facilities and $750 \mathrm{MW}(\mathrm{e})$ of electricity to the regional grid or other local facilities.

It should also be noted that the HTGR technology can be applied in an electricity only application, similar to that of the electricity generating plants on the Waterford site. In this regard, the high temperature operation of the HTGR can achieve higher net generation efficiencies (40 to $50 \%$, depending on the power conversion system deployed) than current light water reactor technologies $(\sim 33 \%)$. The modularity of the HTGR nuclear heat supply system also provides flexibility in sizing the plant and in the scheduling of build out of the plant to correspond with demand growth or retirement of other generation.

The benefits of applying the HTGR technology include the elimination of greenhouse gas emissions that result from the use of natural gas and waste gas in the current energy supplies used by industrial facilities, long term security of the energy supply, and long term stability in the price of the energy. Based on scoping economic analyses, the HTGR cogeneration plant energy price would be equivalent to a natural gas price of $\sim \$ 6 /$ MMBtu (2011\$) based on historical prices of electricity and steam generated using natural gas.

This scoping evaluation provides a basis for a more detailed site feasibility study by any interested entities. Such a feasibility study would include early discussions with the owner of the site, Entergy Louisiana, LLC (ELL), to determine whether and under what terms an HTGR co-generation plant could be located at Waterford, and to resolve the concerns raised by ELL. ${ }^{a}$ Discussions would also be necessary with potential end users of the energy in the area to determine their interest in using the HTGR energy source. The site feasibility study would more thoroughly address the considerations identified in this evaluation and perform detailed economic evaluations using the applicable algorithms and financial factors. If a Project was undertaken to develop the cogeneration plant, the pursuit of an NRC Early Site Permit should be seriously considered, since this process could provide a relatively inexpensive method for resolving site-related issues early in the licensing process. 


\section{ACKNOWLEDGEMENTS}

This report was prepared by Idaho National Laboratory as part of the Next Generation Nuclear Plant Project with the cooperation of Entergy Louisiana, LLC, the owner of the Waterford site, and significant support from Entergy Nuclear, Inc., which suggested use of the Waterford site for this evaluation and supported its completion by directing INL personnel to required information, answering questions on specific characteristics of the site and reviewing drafts of this report. INL wants to thank Entergy Louisiana, LLC for making the Waterford site available for this evaluation and Entergy Nuclear, Inc. for the support in completing it. Idaho National Laboratory also wants to thank The Dow Chemical Company for their support of this evaluation. 


\section{CONTENTS}

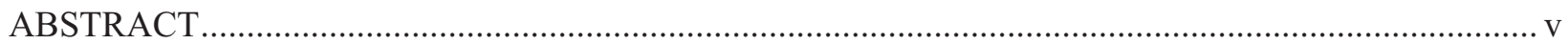

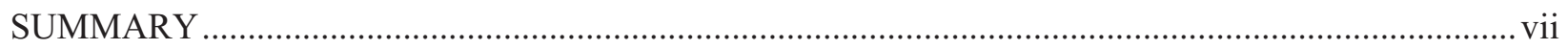

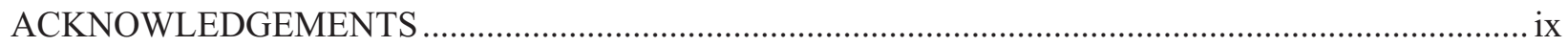

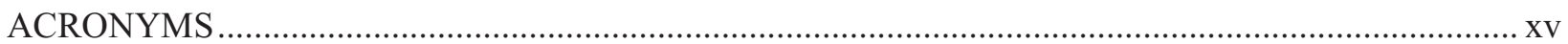

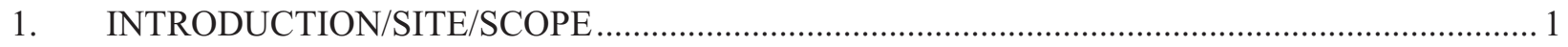

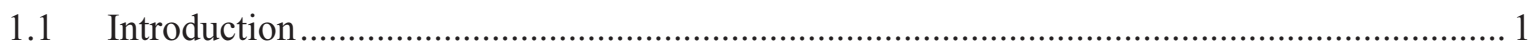

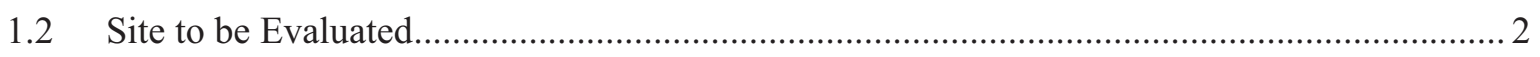

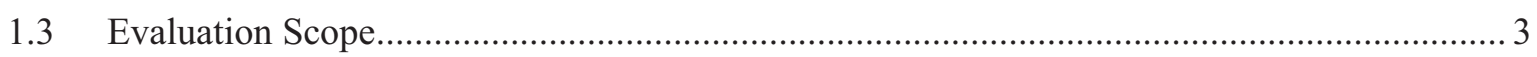

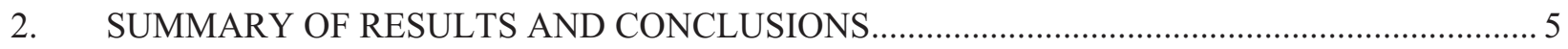

3. EVALUATION FOR SITING AN HTGR PLANT AT WATERFORD-3 …................................. 8

3.1 Location and Specific Site Characteristics Affecting HTGR Plant Siting ........................... 8

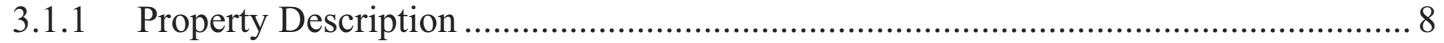

3.1.2 Purchase/Lease Options (Provided by ELL's Real Estate Department) .................... 10

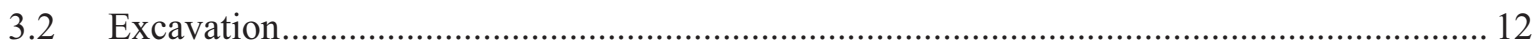

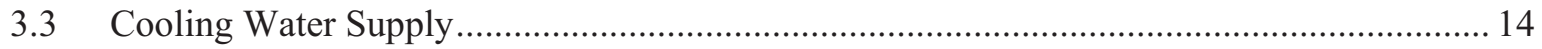

3.4 Transportation and Handling of Large Components....................................................... 15

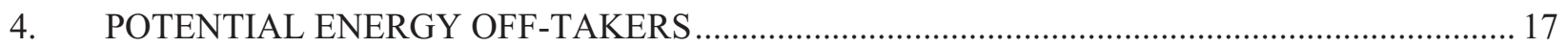

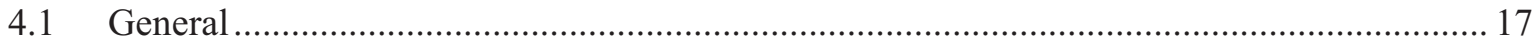

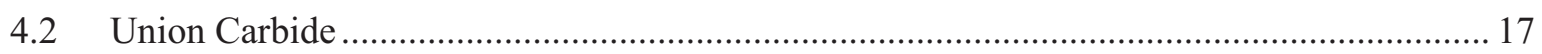

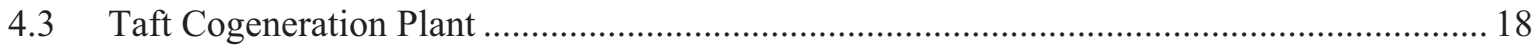

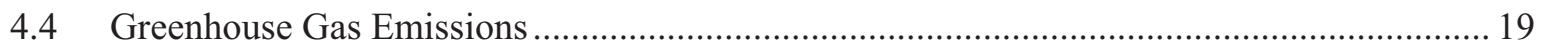

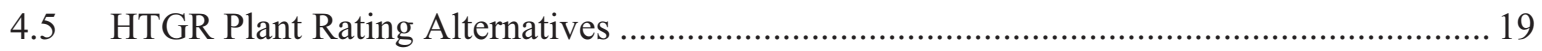

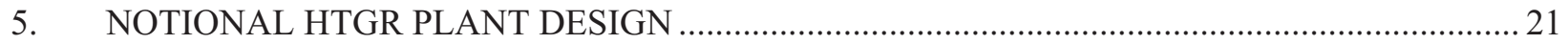

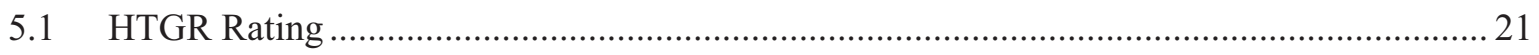

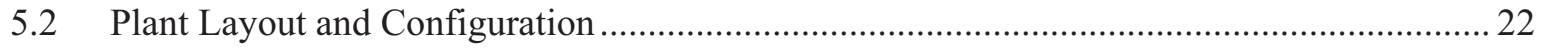

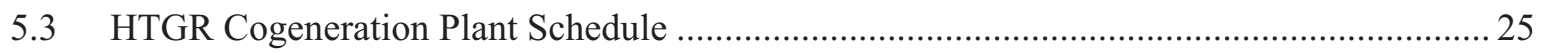

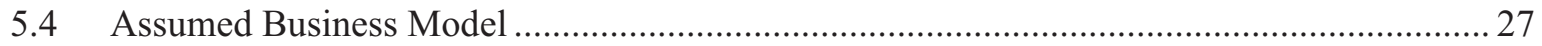

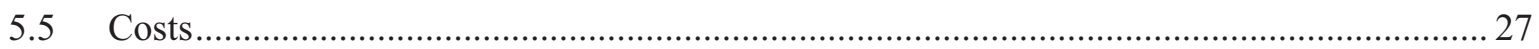

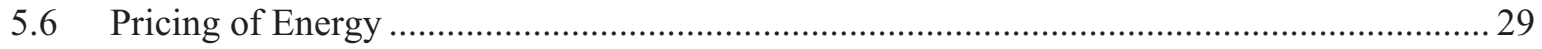

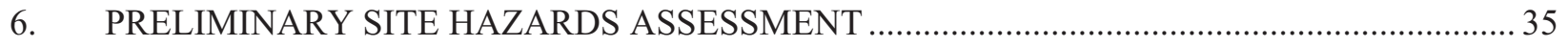

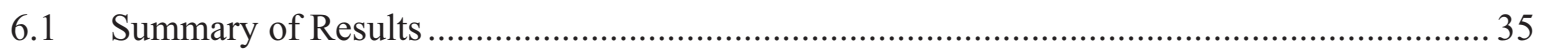

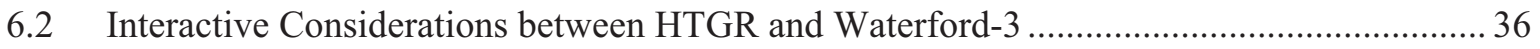

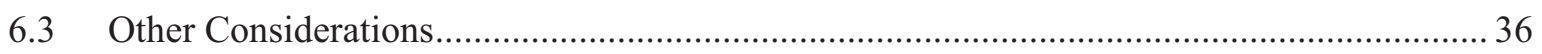

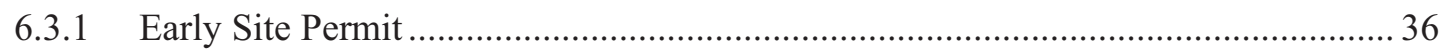




\section{FIGURES}

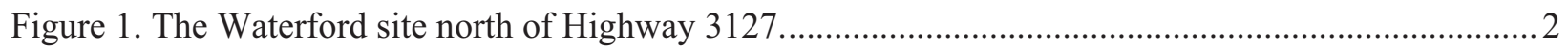

Figure 2. Waterford site and major industrial plants east of Waterford-3 ................................................ 3

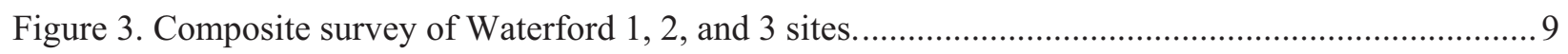

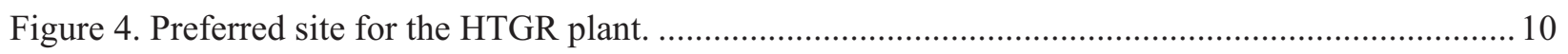

Figure 5. Relationship of preferred and alternative sites for the HTGR plant........................................ 11

Figure 6. Example of nuclear heat supply system embedment.......................................................... 13

Figure 7. Waterford-3 cooling water intake and discharge structures. ................................................. 14

Figure 8. Reactor pressure vessel - the largest vessel anticipated to be used in the HTGR. [General Atomics 911118, "RPV and IHX Pressure Vessel Alternatives Study Report, April 2008"]

Figure 9. A Typical heat transport system vessel. [AREVA, 12-9076324-001 RPV and IHX Ves

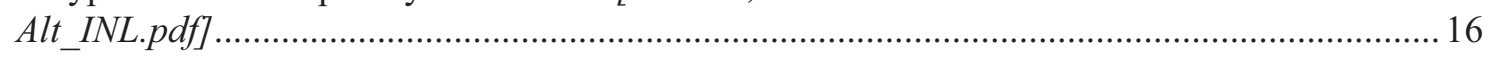

Figure 10. Major industrial facilities located within 5 miles of Waterford-3 nuclear power plant............. 17

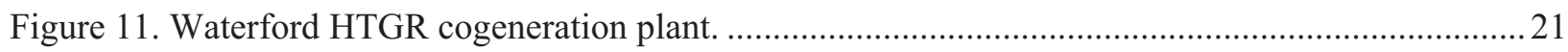

Figure 12. Preconceptual layout of a 4-NHSS module HTGR plant (Visio file: "Waterford-Eval Plant Layouts, Variations in the Number of Modules 8-17-11")............................................ 23

Figure 13. The four-module layout on the preferred location. [Visio file: "Waterford-Eval - Plant

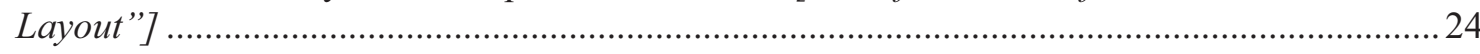

Figure 14. The six-module plant layout on the preferred location. [Visio file: "Waterford-Eval -

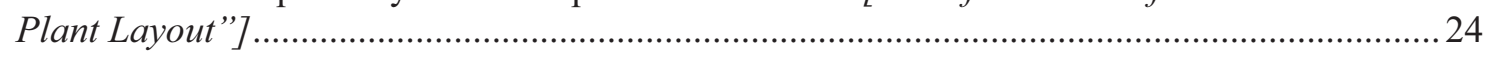

Figure 15. The 10-module layout on the preferred location. [Visio file: "Waterford-Eval - Plant

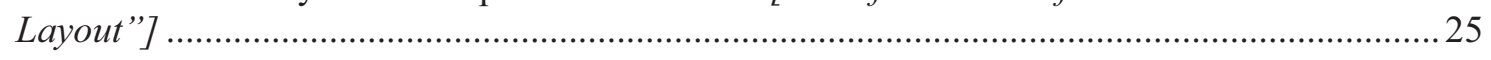

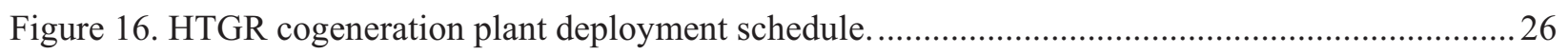

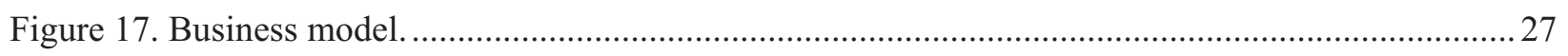

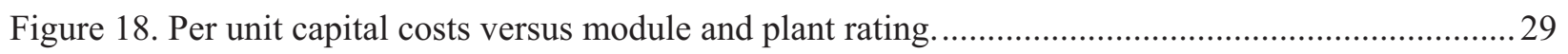

Figure 19. Comparison of HTGR Prices with Natural Gas Plant. ......................................................... 31

Figure 20. Effect of variations in key economic parameters on the price of electricity. ........................... 32

Figure 21. Effect of variations in key economic parameters on the price of steam.................................. 32

Figure 22. Electricity price, \$/MWhe — probability distribution and statistics....................................... 33

Figure 23. Steam price, $\$ / 1,000 \mathrm{lb}$ — probability distribution and statistics.......................................... 34

\section{TABLES}

Table 1. Dow Union Carbide steam and electricity production — 2009 and 2010 .................................. 18

Table 2. Taft cogeneration energy consumption and generation — 2009 and 2010 ................................ 19 
Table 3. Two HTGR plant alternative steam \& electrical supply ratings..............................................220

Table 4. Summary of alternative HTGR plant design characteristics......................................................22

Table 5. Summary of HTGR cogeneration plant estimated capital and operating costs $(2010 \$$

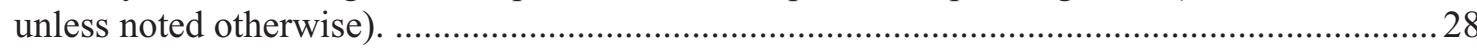

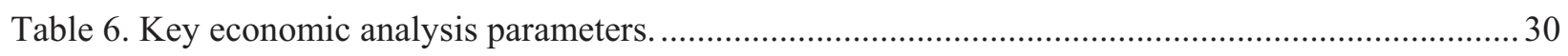

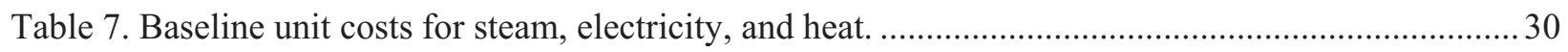




\section{ACRONYMS}

COL Combined Operating License

EAB exclusion area boundary

ECC Energy Education Center

EIA Energy Information Administration

ELL Entergy Louisiana, LLC

EPA Environmental Protection Agency

ESP Early Site Permit

GTCC gas turbine combined cycle

HTGR high temperature gas-cooled reactor

INL Idaho National Laboratory

LWR light water reactor

NGNP Next Generation Nuclear Plant

NHSS nuclear heat supply system 


\section{Next Generation Nuclear Plant Project Evaluation of Siting an HTGR Co-generation Plant on an Operating Commercial Nuclear Power Plant Site}

\section{INTRODUCTION/SITE/SCOPE}

\subsection{Introduction}

This paper summarizes a scoping evaluation conducted by the Idaho National Laboratory (INL) Next Generation Nuclear Plant (NGNP) Project of the technical and economic feasibility of siting a high temperature gas-cooled reactor (HTGR) plant on an existing nuclear plant site that is located in an area where there is significant industrial activity. This is a co-generation application in which the HTGR Plant would be supplying steam and electricity to one or more of the nearby industrial plants.

The NGNP Project was initiated at INL by the U.S. Department of Energy (DOE) as part of the Generation IV Nuclear Energy Systems technology roadmap and pursuant to the Energy Policy Act of 2005. ${ }^{1}$ The principal objective of the NGNP Project is to support commercialization of HTGR technology. The HTGR is helium cooled with a graphite core that can operate at reactor outlet temperatures much higher than conventional light water reactor (LWR) technology. Accordingly, it can be applied in many industrial applications as a substitute for burning of fossil fuels, such as natural gas, in addition to producing electricity-the principal application of LWRs. Applications of the HTGR technology that have been evaluated by the NGNP Project for supplying process energy include supplying electricity, steam, and high-temperature gas to a wide range of industrial processes, and production of hydrogen and oxygen for use in petrochemical, refining, coal-to-liquid fuels and feedstocks, chemical, and fertilizer plants. These evaluations investigated both the technical and economic viability and the market potential for these applications. ${ }^{2,3}$

As a non- $\mathrm{CO}_{2}$-emitting substitute for the burning of fossil fuels in industrial applications, the HTGR can offset significant quantities of $\mathrm{CO}_{2}$ emissions attendant with the burning of these fuels. These emissions derive from both the direct combustion of these fuels in the industrial processes (e.g., providing steam, electricity for internal use, supplying high temperature gas) as well as the emissions associated with electrical power taken from the grid. The use of the HTGR technology as a substitute for burning of natural gas in many of these applications, and for conversion of coal to synthetic fuels and chemical process feedstock, also improves the security of the energy supply in the United States, reduces reliance on offshore imports, reduces the impact of the volatility in energy prices that have been experienced over the last few decades on the economics of industrial processes (e.g., wide swings in the prices of oil, natural gas, and coal), and preserves our limited nonrenewable energy resources (e.g., instead of burning natural gas, it is used in more productive and irreplaceable feedstock applications for producing a broad range of chemicals).

In support of commercializing the HTGR technology the NGNP Project has defined tasks to assess the feasibility of siting the HTGR to support different industrial applications under different site conditions, (e.g., brownfield closely co-located with petrochemical, refining or other industry with high and varied energy usage, brown or greenfield on an existing nuclear site in close proximity to one or more potential energy off-takers, brown-or greenfield in a remote location, greenfield for electricity generation and distribution only.) In other work, the NGNP Project has evaluated siting the HTGR within or close by an existing petrochemical facility. The NGNP Project has also performed preliminary analyses for siting a plant in a remote area, supplying steam, electricity, and high temperature gas for recovery and upgrading of unconventional crude oil. 


\subsection{Site to be Evaluated}

The location selected for this evaluation is adjacent to Entergy Louisiana, LLC's (ELL) Waterford-3 nuclear facility located on the banks of the Mississippi river, in St. Charles Parish, Louisiana. ELL owns $\sim 3,000$ acres on which the Waterford-3 nuclear facility is sited. Three other ELL fossil fired plants (Waterford-1, 2, and 4) are located to the west of Waterford-3 on the ELL property. For the purposes of this report, the overall ELL property will be referred to as the Waterford site. The existing nuclear facility location will be referred to as the Waterford-3 site.

The Waterford site was originally slated for two pressurized water reactor units, but the second nuclear plant was not built. Accordingly, there is significant clear and unused area for siting the HTGR. The site is also surrounded by major industries, including refining, petrochemical, hydrogen generation, ammonia, and other plants. Figures 1 and 2 are aerial views of the Northern part of the Waterford site, the Waterford-1, 2, 3, and 4 plants, and the surrounding industrial plants situated east of the Waterford site.

This being a hypothetical siting evaluation to support NGNP Project objectives in developing and commercializing the HTGR technology, ELL was not consulted to determine if there are future plans for this site that would conflict with the feasibility of siting an HTGR there, since future plans for the site are not relevant to this evaluation. They would be relevant to a follow-up site feasibility study by others; such a study would require early discussions with ELL on their plans for the site.

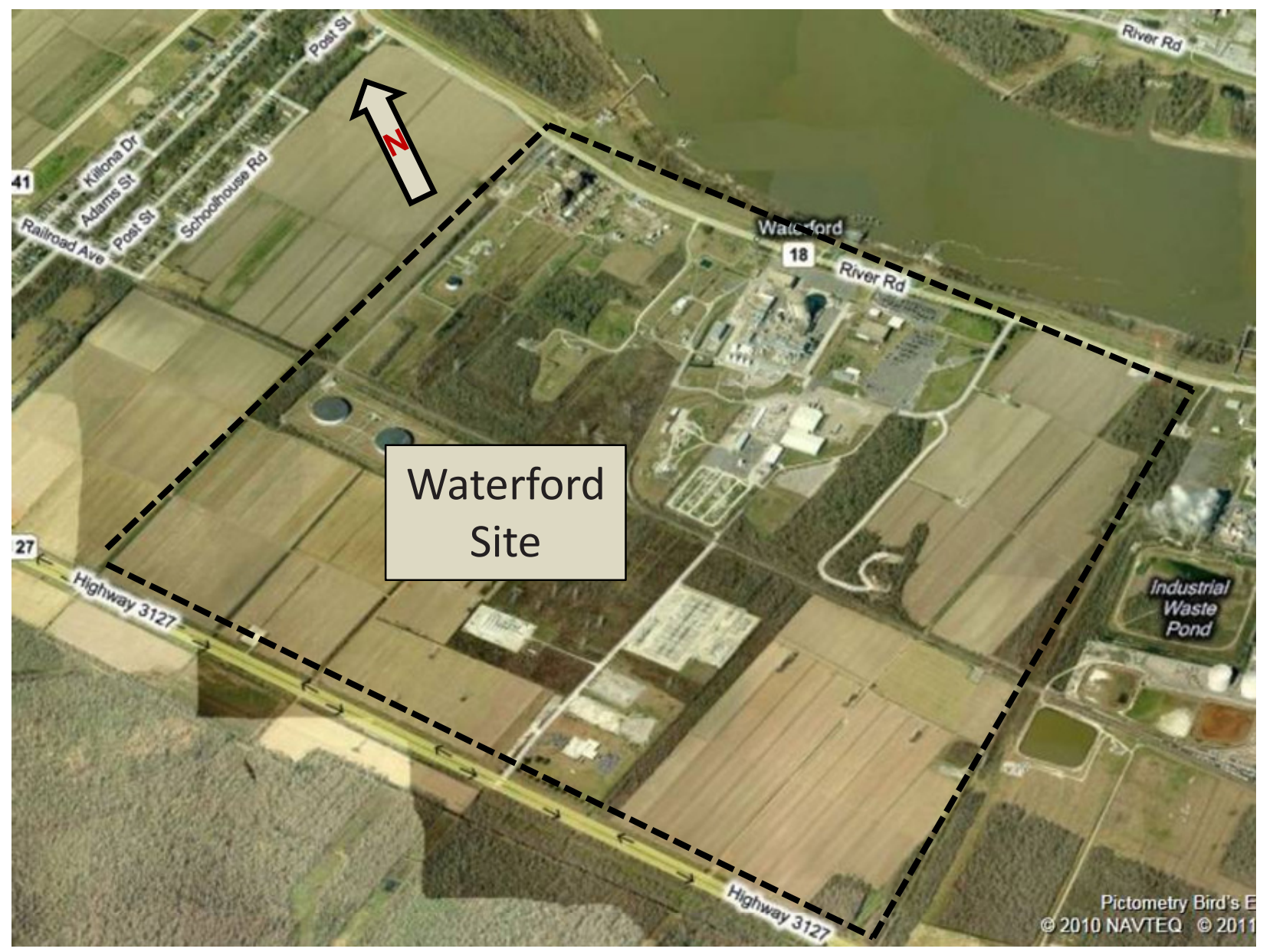

Figure 1. The Waterford site north of Highway 3127. 


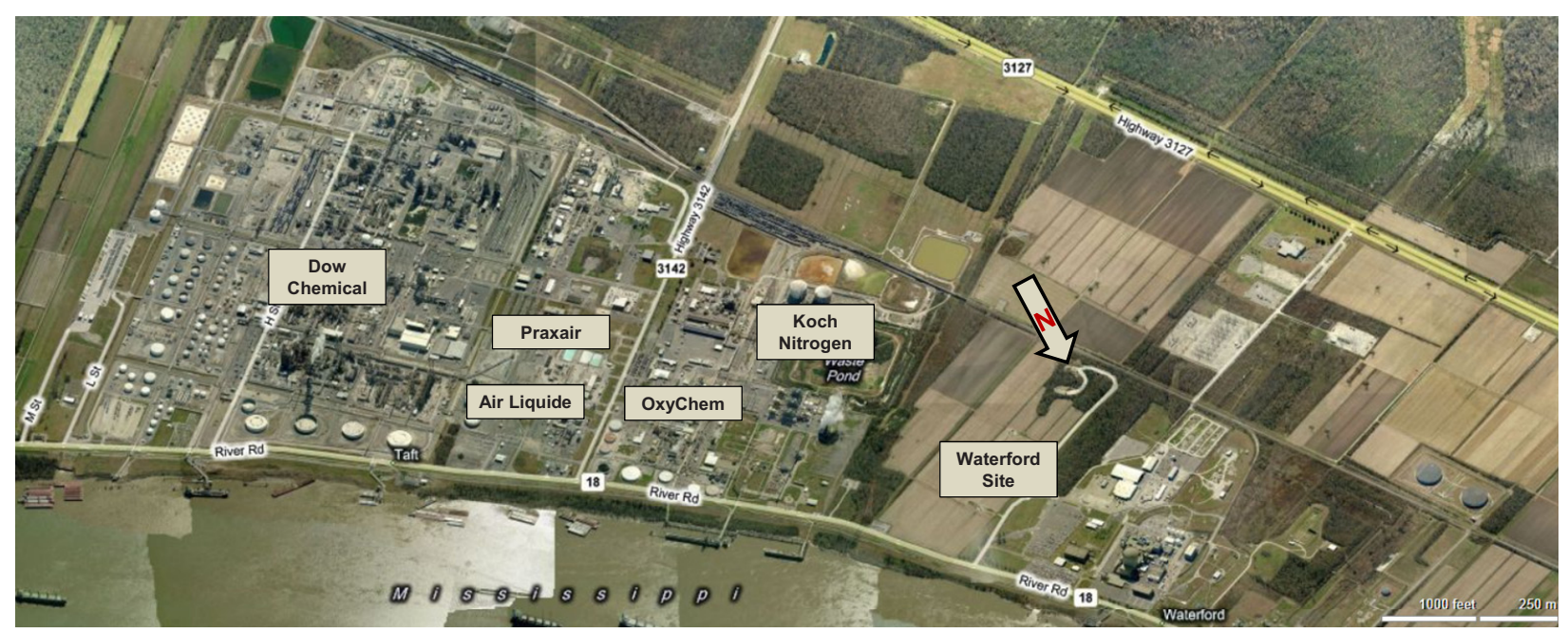

Figure 2. Waterford site and major industrial plants east of Waterford-3.

\subsection{Evaluation Scope}

This evaluation covered the feasibility of locating an HTGR as a co-generation plant supplying steam and electricity to nearby industrial facilities on the Waterford site. ${ }^{\mathrm{b}, 4}$ The feasibility to locate the HTGR plant on the Waterford site was evaluated considering the size of the HTGR plant, the expected exclusion area boundary (EAB) of the plant, the ability to construct the plant on the site with emphasis on the nature and depth of required excavations and site preparation, the use of water extracted from the Mississippi for turbine generator condenser and other auxiliary cooling needs, the availability of additional water sources to meet other plant needs, and the ability to receive and transport large vessels and other major components such as turbine generator shells and rotors to the HTGR plant site.

The location and energy needs of industrial plants (potential end users) close by the selected site were identified and assessed for supply by an HTGR plant. This included understanding the amount of energy required, the peak to average and minimum to average annual variations in demand, the forms of energy required (e.g., steam, electricity and hot gas), the availability requirements, and the potential for selling excess generated electricity to the local electrical grid. The majority of this information was obtained from publically available DOE Energy Information Administration (EIA) data. This effort did include meeting with a potential energy off-taker to elicit their interest in considering the HTGR as a long term energy supply and the types and amounts of energy that would be required.

Once the energy needs of potential end users was understood, a conceptual HTGR plant design was developed with the capability to meet these energy needs, including forms of energy, reliability, and availability. Scoping analyses were also performed for this plant design to evaluate the economic viability of this application.

The HTGR technology could also be applied in an electricity-only application similar to that of current electricity generating plants on the Waterford site. In this regard, the high temperature operation of the HTGR can achieve much higher net generation efficiencies (40 to $50 \%$, depending on the power conversion system deployed) than current LWR technologies ( $30 \%)$. The modularity of the HTGR nuclear heat supply system also provides flexibility in sizing the plant and in scheduling build-out of the

b. Per EPAct Sec 642(b)(3) "INL shall review and assess the functional, operational, and performance requirements for hightemperature, gas-cooled nuclear energy technologies and possible industrial applications for the technologies as identified by end-users, owner/operators, and investors to support the Project." 
plant to correspond with demand growth or retirement of older generation reactors. This evaluation, however, covered the broader cogeneration application in accordance with the NGNP Project objective of commercializing the HTGR technology for industrial applications.

In support of this evaluation, a separate site assessment was performed to determine hazards and potential challenges to licensing the plant with the U.S. Nuclear Regulatory Commission (NRC) that site owners and HTGR designers need to be aware of when developing the HTGR design for this site, and to evaluate the site for suitability, considering certain site characteristics. The scope of the HTGR site hazard assessment included

- Completing an initial screening to identify potential challenges and restraints to be addressed in design and licensing processes

- Providing assurance that the HTGR technology can be deployed for a range of applications for a variety of sites

- Describing actions necessary to mitigate the impacts of hazards

- Providing key insights that can inform the plant design process.

This assessment considered health and safety, environment, sociology, and other important siting characteristics to determine the potential impact of identified hazards and potential challenges presented by the location for licensing this technology with NRC. This assessment also identified interactive effects between Waterford-3 and the HTGR that would need to be considered in the site suitability evaluation for the HTGR plant. 


\section{SUMMARY OF RESULTS AND CONCLUSIONS}

The evaluations summarized in this report did not identify any technical hazards or economic conditions that would prevent locating an HTGR cogeneration plant on the Waterford site for supplying steam and electricity to at least two closely located industrial plants and electricity for sale on the regional electrical grid. Specifically:

- Preliminary interest in receiving energy from a co-generation plant on the Waterford site has been shown by The Dow Chemical Company petrochemical plant located within 1-1/2 miles of the potential site for the HTGR plant.

- The Waterford site has several locations with sufficient area and acceptable geological and hydrological characteristics to permit siting of the HTGR plant. These locations also permit siting the HTGR plant at sufficient distances from the Mississippi river to satisfy US Army Corps of Engineer restrictions on construction within $1,500 \mathrm{ft}$ of the river levee centerline and from the railway on the south side of the Waterford site to accommodate potential hazards from postulated exploding railcars without requiring special design features.

- The HTGR plant can be located such that its expected EAB at 400 meters from the reactor centerlines does not encompass the Waterford-3 nuclear power plant nor extend outside the boundaries of the Waterford site. Because it is expected that all regulatory requirements for protecting the health and safety of the public and the environment, including the Environmental Protection Agency's (EPA) Protective Action Guidelines, will be met at the EAB it is anticipated that the coverage area of current Waterford-3 emergency planning would not need to be increased. However, the proximity of the HTGR plant would need to be considered in updates to the Waterford-3 emergency plan.

- The ability to handle the large components of the HTGR plant and the ability to construct the HTGR plant on the Waterford site have been confirmed. Should a project to site an HTGR plant on the Waterford site evolve, discussions with the US Army Corps of Engineers would be necessary to confirm the acceptability of the excavation and dewatering that would be necessary to bury the nuclear heat supply systems $160 \mathrm{ft}$ underground. Based on information gathered and prior excavation experience on the Waterford site, a favorable disposition by the Corps for these excavations and dewatering would be expected.

- It has been assumed that major cooling water requirements for the plant, (e.g., power conversion system condenser cooling) could be satisfied by extraction from the Mississippi river in a once through configuration similar to that in operation at Waterford-3. However, if a determination is made that the HTGR plant is a new unit at an existing generating plant, recent EPA rulings may require the use of a closed cooling water system. If this is the case an evaluation would be made as part of the plant design process to determine the most efficient and economic closed cooling water system for the HTGR plant (e.g., natural draft cooling tower, forced draft cooling). In any event, there is adequate water from the Mississippi river to support a once through or closed cycle condenser cooling water configuration.

- It has also been assumed that other water usage requirements can be met using the St. Charles Parish water supply. Waterford-3 uses $\sim 12$ million gallons annually from this source. No extractions from groundwater or local aquifers were assumed. If a site feasibility study concluded that the St. Charles Parish water supply was not sufficient to satisfy an HTGR plant, a study would be needed to determine if ground water would be sufficient to supply the HTGR plant under all conditions and would not lead to excessive ground subsidence.

- A review of the DOE/EIA data for the industrial facilities located on the same side of the river and within two miles of the Waterford site identified only two facilities with sufficient energy generation capacity and consumption to be considered as potential off-takers of energy from an HTGR 
cogeneration plant. These are The Dow Chemical Company petrochemical plant and the Taft Cogeneration plant. A 3,600 MW(t) plant rating using 6-600 MW(t) HTGR modules was determined to be sufficient to replicate the energy supplies at these facilities and to provide the best economics of several alternatives evaluated. This HTGR plant would be capable of supplying all of the energy needs of these facilities as well generating up to $730 \mathrm{MW}(\mathrm{e})$ of additional electricity for sale on the regional grid. This excess capacity and the provision of six modules also provides $100 \%$ availability of steam and electricity to the industrial facilities during HTGR plant refueling and maintenance outages.

- A notional schedule was developed for the design, licensing, construction, and commissioning of the HTGR plant showing the length of Projects entailing 4, 6, and 10 module configurations. The total estimated time from the start of the project to initial operation of the first of the six $600 \mathrm{MW}(\mathrm{t})$ modules is estimated at 10 years, which includes 6 years of licensing and permitting activities and 4 years of construction. Licensing is assumed to be conducted under 10 CFR 52 with eventual issue of a Combined Operating License (COL). It is also assumed that an Early Site Permit (ESP) will be obtained. Site preparation is assumed to start upon receipt of the ESP 2 years prior to receipt of the COL. All six modules would be online in an additional 2-1/2 years. This schedule and plant configuration was the basis for the economic analyses of this plant.

- In the assumed business model for the cogeneration plant, the HTGR plant is a standalone entity. In developing the business model it was assumed that long term energy supply agreements could be executed with the potential end users for supplying steam and electricity. The terms of these agreements would include provisions for price adjustments based on inflation and favorable factors for continuous extension of the energy supply contracts. It was also assumed that similar contracts could be executed with the regional utility and potentially other facilities in the area for supplying electricity.

- Economic evaluations show that the HTGR plant can provide steam and electricity at prices that provide acceptable returns on equity to the equity holders and are competitive with historical and projected prices of steam and electricity generated using natural gas fired plants. Baseline and uncertainty analyses predict the following ranges of electricity and steam prices from the HTGR plant:

- Electricity $64 \pm 10 \$ / \mathrm{MW}(\mathrm{e})-\mathrm{hr}$

- Steam $10 \pm 1.5 \$ / 1000 \mathrm{lb}$

The baseline prices are comparable to a natural gas price of $\$ 6 / \mathrm{MMBtu}$ based on historical data.

The ranges of the prices reflect the large uncertainties in the cost and financial factors used in the economic evaluations. As the HTGR plant design progresses, these uncertainties will be reduced, developing more confidence in the results.

The separately documented site hazards analysis concludes that the Waterford site appears to be viable for siting the HTGR plant. This assessment identified questions concerning technical and environmental factors that require further evaluation prior to proceeding with formal site permitting and HTGR deployment. The more significant of the questions that could affect the HTGR plant design and construction mitigation actions are:

- The proximity of a nearby railroad line to the site presents potential issues with respect to impacts from hazardous materials and security. Physical security considerations may create some specific needs for the design, and will require further evaluation, depending on the final location selected for siting the reactors and the surveillance technology selected. 
- The site exhibits near surface groundwater conditions in soils that are prone to settlement when dewatered. This can create a risk of localized surface subsidence during the dewatering operations that would accompany construction and potentially operation of an HTGR facility.

- Equilibrated groundwater hydrodynamic pressures on the basemat (at approximately 160-ft deep) of the post-constructed HTGR facility must be considered in the HTGR facility design.

- Current and future planned flood protection and mitigation features in the vicinity of the site, such as levee systems, reservoirs, and diversion structures maintained by the U.S. Army Corps of Engineers, would need to be revalidated as applicable to adequate flood protection for newly installed HTGR modules at this site.

All of these would require further evaluation during the design process but are judged not to disqualify this site for locating the HTGR plant.

Note that this summary listing does not include other challenges and potential hazards on or around the Waterford site, such as the bulk storage of hazardous substances at neighboring industrial facilities. Although these are important considerations for HTGR design and siting, they were not considered to be significant HTGR challenges, since they have previously been successfully addressed at Waterford-3 and can likely be similarly addressed for the HTGR facility.

An assessment was also performed to identify impacts that the construction and operation of the HTGR facility may have on the existing Waterford-3 nuclear plant. The results of that assessment include a number of items, including the following examples that need to be evaluated further, but are judged based on this assessment to not disqualify this site for locating the HTGR plant.

- Effects of postulated HTGR radiological releases on the existing safety systems, technical specification requirements, and associated dose analyses

- The potential need to integrate the security and emergency planning functions for Waterford-3 and the HTGR facility

- Hazards or impacts to be considered during the HTGR facility's construction phase (site access/egress, excavation, wind-generated, construction-related missiles, etc.)

This scoping evaluation provides a basis for a more detailed site feasibility study by any interested entities. Such a study would more thoroughly address the considerations identified in this evaluation and perform detailed economic evaluation using appropriate corporate algorithms and financial factors. If a Project was undertaken to develop the cogeneration plant, the pursuit of an NRC ESP should be seriously considered, since this process provides a relatively inexpensive method for resolving site-related issues early in the licensing process. 


\section{EVALUATION FOR SITING AN HTGR PLANT AT WATERFORD-3 \\ 3.1 Location and Specific Site Characteristics Affecting HTGR Plant Siting}

\subsubsection{Property Description}

The Waterford site is on the west bank of the Mississippi River between Killona and Taft, Louisiana in the northwest portion of St. Charles Parish. This real estate consists of approximately 3,632 acres. The property is bounded on the north side by the Mississippi River with 7,500 ft, more or less of river frontage. State Road 18, also known as River Road, and the Missouri Pacific Railway cross the width of the property. Waterford is located in an industrial area. There are three generating stations on the site that are owned by ELL. In addition to Waterford-3, these facilities include the Waterford Units One and Two. These units are fossil-fired drum-type boilers, each having their own turbine-generator sets. Waterford Unit Three is a pressurized water reactor having its own turbine/generator set. It is located downstream of the fossil units on State Highway 18. Included in each plant's design are fuel storage tanks and support structures, parts storage and warehousing, administration and personnel buildings, maintenance buildings and support structures. An Energy Education Center (ECC) is located on State Highway 3127. The EEC provides facilities for classroom and technical laboratory instruction. It is also the home to a full-size control room simulator identical to that of the Waterford-3 control room and is used for operator and technical training. Also located in the EEC is the near-site Emergency Operations Center.

The site was originally sized to include two nuclear units along with the two fossil plants, but only one nuclear plant was built. The tract of land owned by ELL is adjacent to large industrial facilities that are sandwiched between River Road (State Road 18) and State Highway 3127. A parcel of the property of approximately 2,352 acres is located south of State Highway 3127. It is undeveloped and considered to be freshwater forested wetlands.

Figures 1 and 2 (above) provide aerial views of the Waterford site and nearby industrial facilities. ${ }^{c}$ Figure 3 is a copy of a recent survey of the Waterford site. In reference to Figure 3, an objective of siting the HTGR plant is to be north of the Texas \& Pacific railroad tracks and on the eastern side of Waterford-3 to facilitate circulation of cooling water to and from the river and transport of steam to the industrial plants. This places the preferred site in Section 25 of the survey map (see Figure 3). Figure 4 is an aerial view highlighting this section with an outline of the area that was originally considered as a location for the HTGR plant. Also shown is an outline of the preferred area considering restrictions on siting. It was learned, for example, that the site must be at least 1,500 ft from the center of the levee to be in compliance with U.S. Army Corps of Engineer's restrictions on construction near the Mississippi river. The area outlined for the preferred site is also judged to be sufficient to accommodate the size of the HTGR plant needed to meet the energy needs of local industries. As shown on Figure 4, the potential site has been located in the south-western edge of Section 25. This is outside the zone of restriction on construction within $1,500 \mathrm{ft}$ of the center of the levee but does overlap with natural gas pipelines that traverse that part of the site. It may be possible to position the plant within this area without interfering with these gas lines. If necessary, the western most pipeline could be rerouted to accommodate the HTGR plant.

c The photographs of the Waterford site and surrounding area are for reference only and may not show the latest configurations of Waterford-3 or other facilities. 


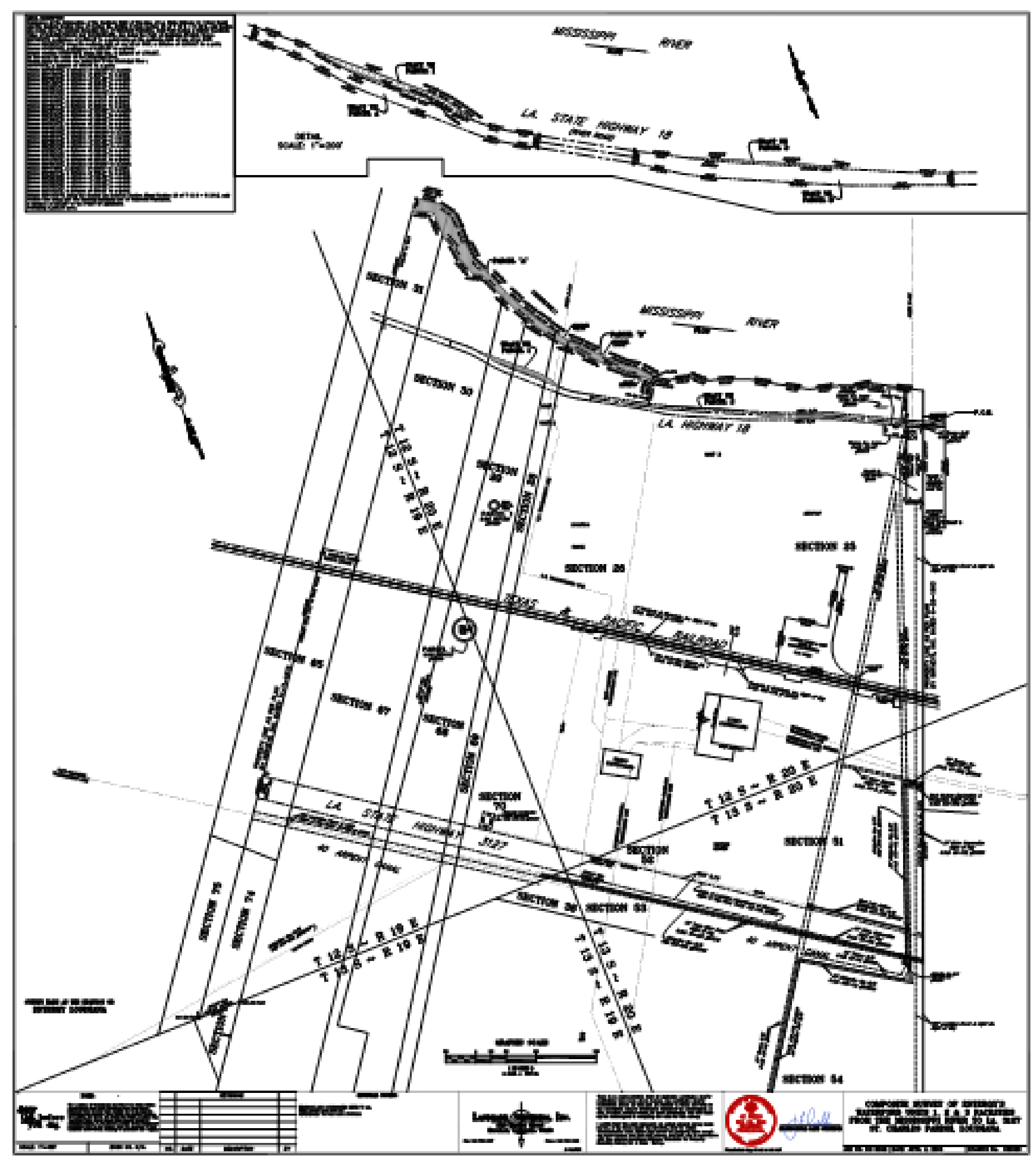

Figure 3. Composite survey of Waterford 1, 2, and 3 sites. 


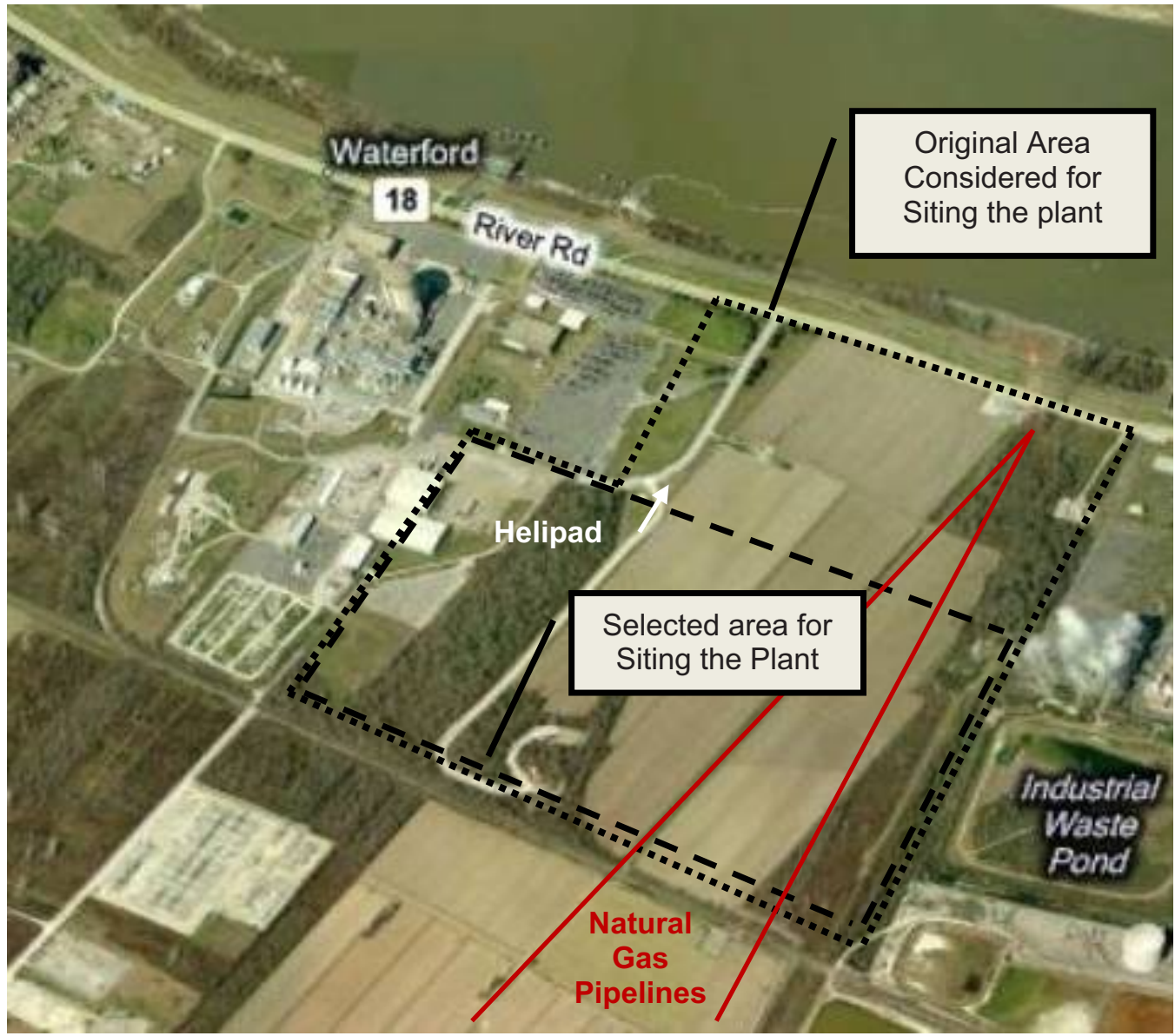

Figure 4. Preferred site for the HTGR plant.

Figure 5 shows alternative site locations that have been identified as feasible for the HTGR plant and could be investigated further if necessary in the future. The preferred site and the alternative sites are close enough together that there is little difference in site characteristics such as soil composition and geology, seismology, access to the regional grid, and access to the industrial facilities and the Mississippi river. If the alternative sites were considered, the preferences to minimize the logistics and distances for steam transport to the industrial facilities east of the plant would be Site X, then Y, and then Z.

The following section summarizes considerations on purchase or lease of property on the Waterford site for siting a cogeneration plant provided by ELL. These were not considered in this scoping evaluation because this is a hypothetical siting evaluation to support NGNP Project objectives in developing and commercializing the HTGR technology. Accordingly, future plans for the site are not relevant to this evaluation. They would be relevant to a follow-up site feasibility study by others and such a study would require early discussions with ELL on their plans for the site.

\subsubsection{Purchase/Lease Options (Provided by ELL's Real Estate Department)}

Options and requirements for a property purchase or lease are expected to be based upon the plant's use as either a regulated asset (benefit for regulated utility ratepayers) or a merchant plant sited solely for the benefit of industrial off-takers. Federal Energy Regulatory Commission rules will apply, depending upon the plant's use as either a regulated or merchant facility. 


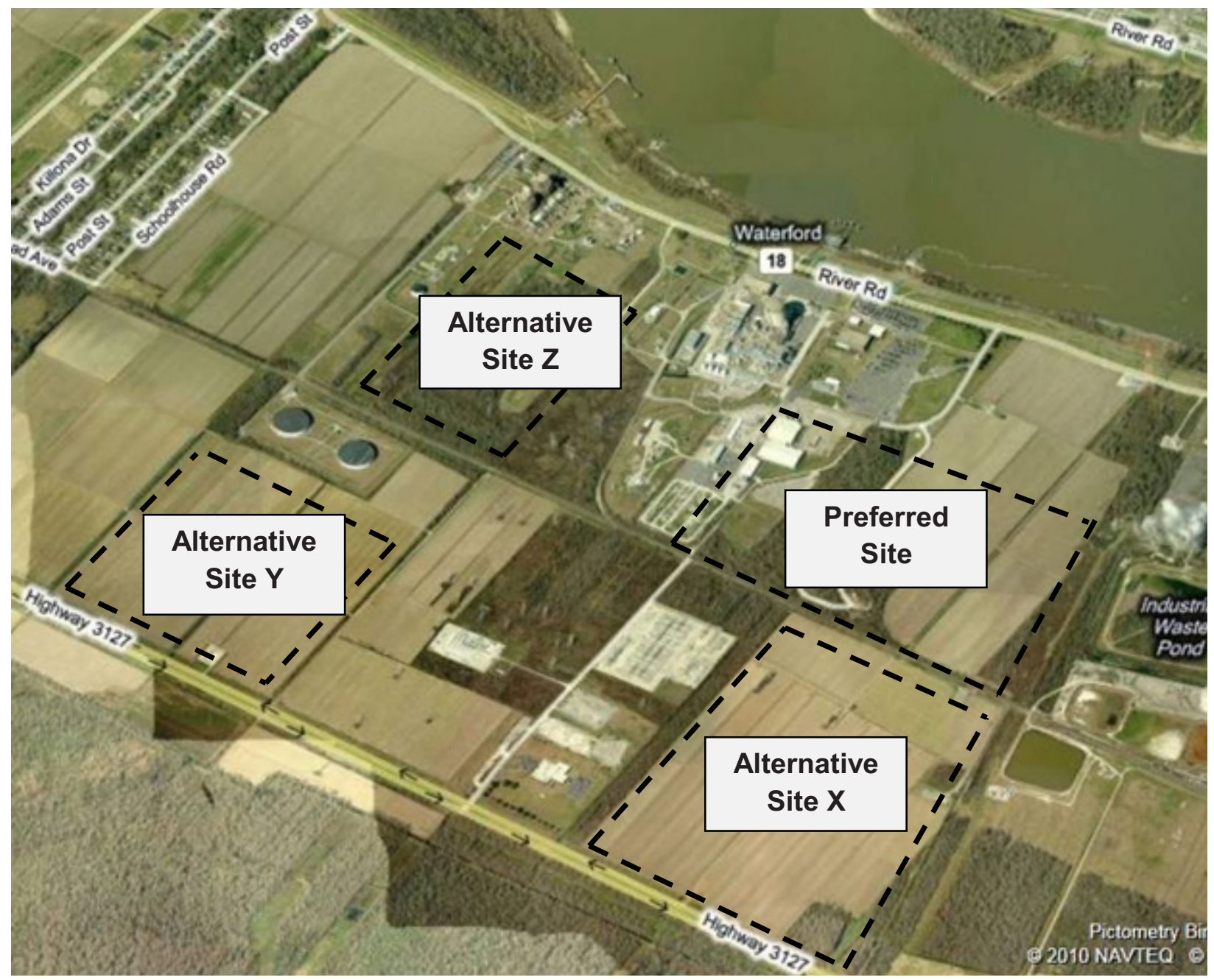

Figure 5. Relationship of preferred and alternative sites for the HTGR plant.

Two options may be available to sell a portion of the Waterford property or lease a portion for industrial use. An agreement such as a lease or license could be executed between ELL companies (regulated and unregulated) or an owner consortium or joint venture. Any agreements would be subject to all appropriate laws, regulatory requirements, and governmental approvals. Compensation/rent would be established in accordance with affiliate rules pricing if a transaction occurs between two ELL affiliates. A real estate transaction would require that compensation be based on current market value for the property, or higher, depending on the type of transaction.

The following principal recommendations on the location of the HTGR plant were developed based on information gathered during the evaluation:

- The site must be located at least 1,500 ft south of the center of the levee on the Mississippi river as required by the U.S. Army Corps of Engineers

- The land North of the helipad (see Figure 4) and east of the Generation Support Building is declared as culturally sensitive land and any type of construction (including a parking lot) is prohibited.

- Two Chevron natural gas lines traverse the ELL controlled land. These lines are located near the transmission towers on the east side of Waterford-3 (see Figure 3). The HTGR plant must consider postulated explosion analysis and blast effects on plant structures and components. (Note that a full 
hazards analysis would be required considering all potential external hazards within 5 miles of the final HTGR site. A preliminary hazards analysis has been performed for the preferred HTGR site shown in Figure 3. ${ }^{5}$ The key conclusions of this analysis are summarized in Section 6 of this report.

- There are two Texaco natural gas pipelines that traverse the preferred site location for the HTGR plant (see Figure 4). These may need to be rerouted if they interfere with the HTGR site. They must also be included in the HTGR hazards analysis (see Section 6).

- The Waterford-3 site hazards analysis includes the postulated explosion of a tanker railcar on the Texas \& Pacific railway tracks south of the plant. This analysis shows no significant effect of the postulated explosion on structures more than 1,100 ft from the tracks. The preferred site and alternative sites $\mathrm{X}$ and $\mathrm{Y}$ may position the HTGR plant closer than 1,100 ft from the tracks. If this is the case the final design of the plant will need to include features to accommodate the predicted blast effects and effects on operating personnel from such an accident.

- It may be feasible and beneficial to extend the Waterford-3 security owner controlled area to include the HTGR plant to consolidate the security forces of the two plants. A separate study will assess the technical, licensing, and any other relevant factors affecting the feasibility of this approach.

- Rights-of-way will need to be obtained through industrial plants that may be in the route for transfer of steam and electricity from the HTGR plant to other industrial plants (see discussion of potential energy off-takers below).

\subsection{Excavation}

As shown in Figure 6 the HTGR nuclear heat supply system (NHSS), which is comprised of the reactor and the heat transport system of each HTGR module, are assumed to be buried underground. The excavation depth for each NHSS module to be included in the plant will be in the range of $160 \mathrm{ft}$, including the basemat. The excavation for each module is cylindrical with a nominal outside diameter of $\sim 110 \mathrm{ft}$.

Note that the HTGR plant does not have to be located completely underground. If necessary it could be located with lesser embedment. There are security and seismic advantages to providing as full an embedment as achievable.

The relevant site geology is summarized in the site Hazards Analysis. No major issues with excavation to the $160-\mathrm{ft}$ depth required to accommodate each NHSS module have been identified. There are several factors that will need to be addressed in detail as the design and siting of the plant are finalized:

- The depth of the excavation will be below the level of the Mississippi river in that area. Any special precautions or actions that will be necessary to accommodate this depth will be reviewed with the US Army Corps of Engineers as the design is finalized. None are known at this time.

- The excavation will require caissons and significant dewatering capacity during excavation. It should be noted that Waterford-3 is situated well below the water table and plant personnel indicate that there were no major problems because of that condition during construction. The HTGR plant may require dewatering during operation.

- The potential interaction of the excavation for a module with the operating Waterford-3 plant and other operating sister HTGR module(s) must be evaluated and assessed as part of the design and licensing bases for Waterford-3 and the operating HTGR plants.

- No excavation can be performed within 1,500 ft of the center of the levee on the Mississippi river. The preferred site and other potential sites are south of this limit. 


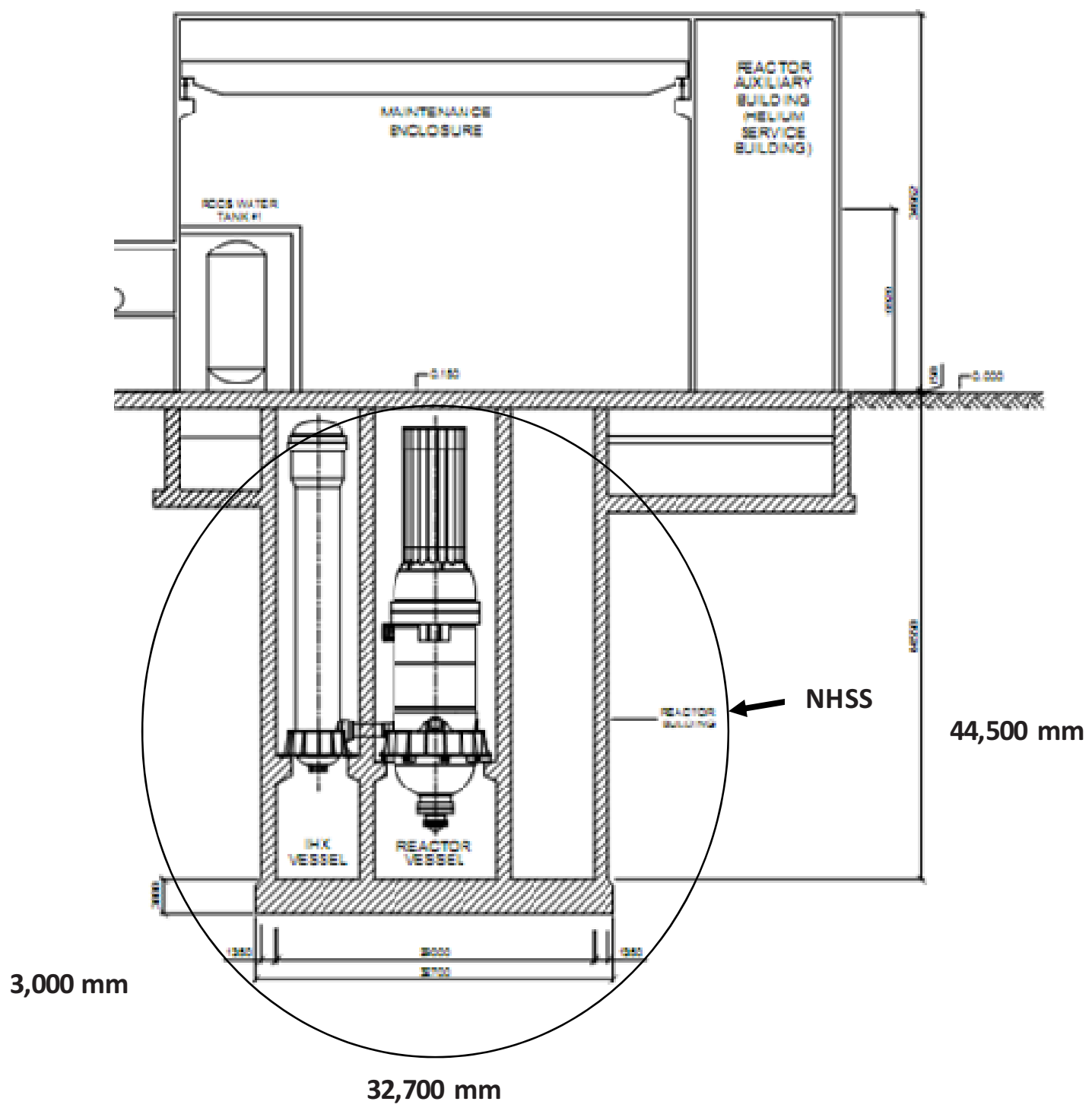

Figure 6. Example of nuclear heat supply system embedment.

- Based on recent excavation experience on the Waterford site, it has been assumed that it will be possible to spread waste dirt from the excavations over existing land. A single module excavation will remove about $1 / 2$-acre $\mathrm{ft}$ of dirt. A more detailed evaluation will be required to locate viable sites for spreading this amount of dirt. The area south of Route 3127 may be viable as a means of offsetting erosion in the wetlands.

- Inspections and tests will be required to ensure that the excavated dirt is not chemically or radiologically contaminated (e.g., from any source from Waterford-3).

- Settling ponds will likely be required for silt removal prior to discharging the water removed during excavation to the drainage canal.

- There is a restriction on any construction activity on the Waterford site if the Mississippi river water level (at the Carrollton gauge) is $+11 \mathrm{ft}$ or higher. 


\subsection{Cooling Water Supply}

For the maximum plant rating being considered for this site and fully rated turbine generators $\sim 1,100 \mathrm{MW}(\mathrm{t})$ or 3,740 MMBtu/hour of cooling will be required. The following factors affect this cooling water supply:

- The Waterford-3 condenser cooling water system is in a once through configuration using Mississippi river water as the coolant. It has been assumed in this evaluation that this same configuration would be acceptable for the HTGR plant. However, recent EPA rulings may require the use of a closed cooling water system if a determination is made that the HTGR plant is a new unit at an existing generating plant. If this is the case an evaluation would be made as part of the plant design process to determine the most efficient and economic closed cooling water system for the HTGR plant, (e.g., natural draft cooling tower, forced draft cooling). In any event, there is adequate water from the Mississippi river to support a once through or closed cycle condenser cooling water configuration.

- For the once through configuration assumed in this evaluation the following apply:

- There is a restriction on the temperature of the water returned to the river of $18^{\circ} \mathrm{F}$ above the inlet temperature. Accordingly, the maximum required cooling water flow for the HTGR condensers would be in the range of $210 \mathrm{MMlb} /$ hour. This is comparable to the flow through condensers in Waterford-3.

- New intake and discharge structures similar to those currently in place for Waterford-3 would need to be constructed over the river levees (see Figure 7).

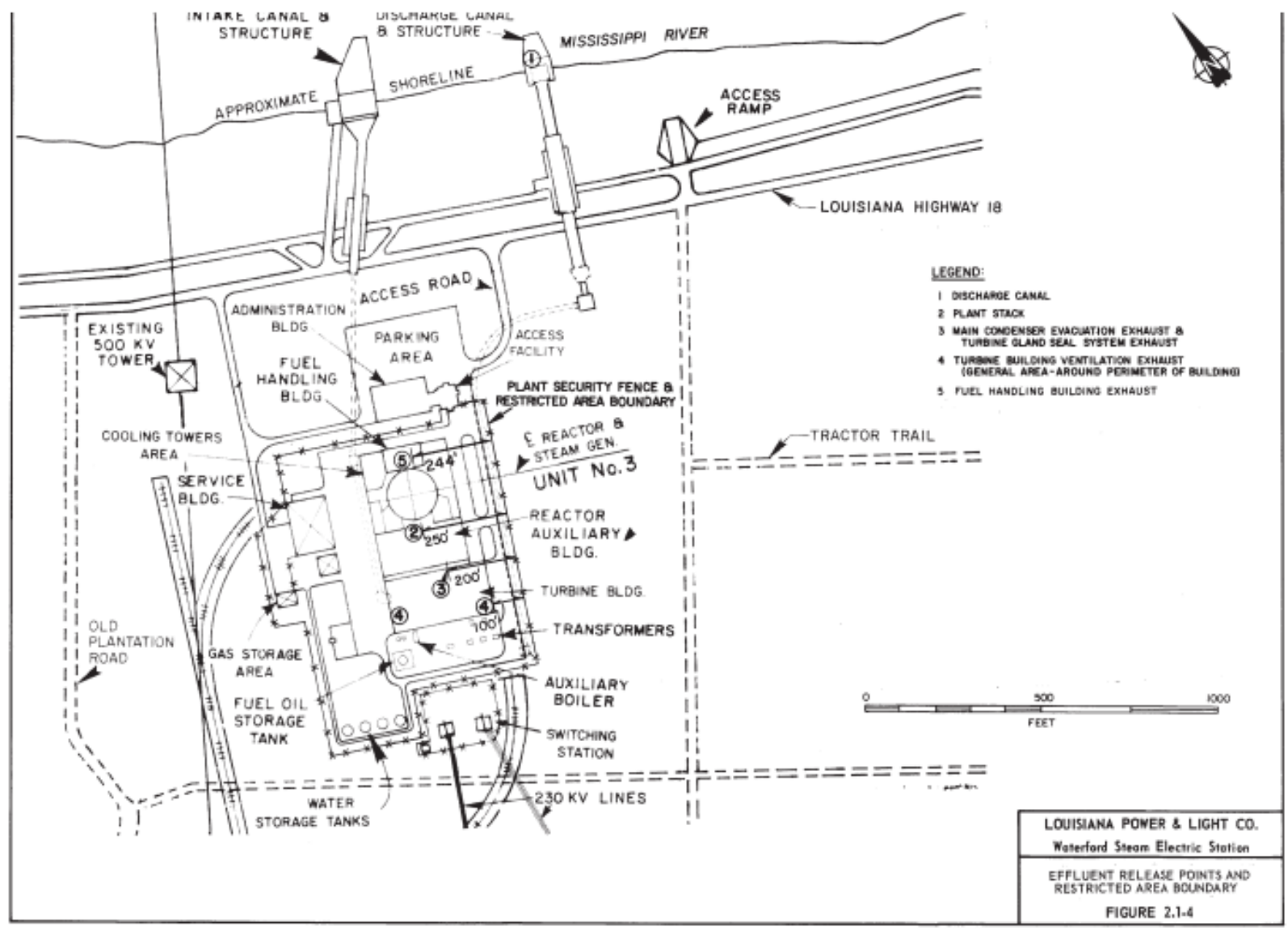

Figure 7. Waterford-3 cooling water intake and discharge structures. 
Additional water supplies will be required for the HTGR plant, (e.g., domestic water supply, makeup to the HTGR shutdown cooling system, turbine generator system, and any other cooling water systems). Waterford-3 currently purchases water not obtained from the river from St. Charles Parish water supply. This amounts to $\sim 12$ million gallons per annum. This has been assumed to be the approach that will be taken for the HTGR plant. Although the water usage needs of the HTGR plant have not been established, they are not expected to be higher than that required of the Waterford-3 plant. Since another plant similar to Waterford-3 was to be included on the Waterford site it is anticipated that the St. Charles Parish water supply will be capable of meeting the HTGR water needs.

It should be noted, however, if sufficient water cannot be obtained from the St. Charles Parish water supply and extraction of water from the groundwater aquifers is needed, an additional study would be required to determine if adequate water can be supplied during all postulated conditions without impacting other users or causing ground subsidence.

\subsection{Transportation and Handling of Large Components}

The largest components in the HTGR plant will be the reactor pressure and heat transport system vessels. These are shown in Figure 6. The heat transport system vessel is shown as enclosing an intermediate heat exchanger (IHX). There is also a cross-over vessel that connects the reactor pressure vessel with the heat transport vessel; however, this vessel is much smaller than the other two vessels and is not judged to require special handling. The reactor pressure vessel is the largest and heaviest of the vessels that will need to be handled during construction of the plant. Figure 8 shows the maximum expected size of the reactor vessel for each NHSS. Figure 9 shows a typical heat transport system vessel dimensions. This vessel will not be as heavy as the reactor pressure vessel sections shown. Note that the weights are in metric tons $(2,250 \mathrm{lb} /$ metric ton $)$.
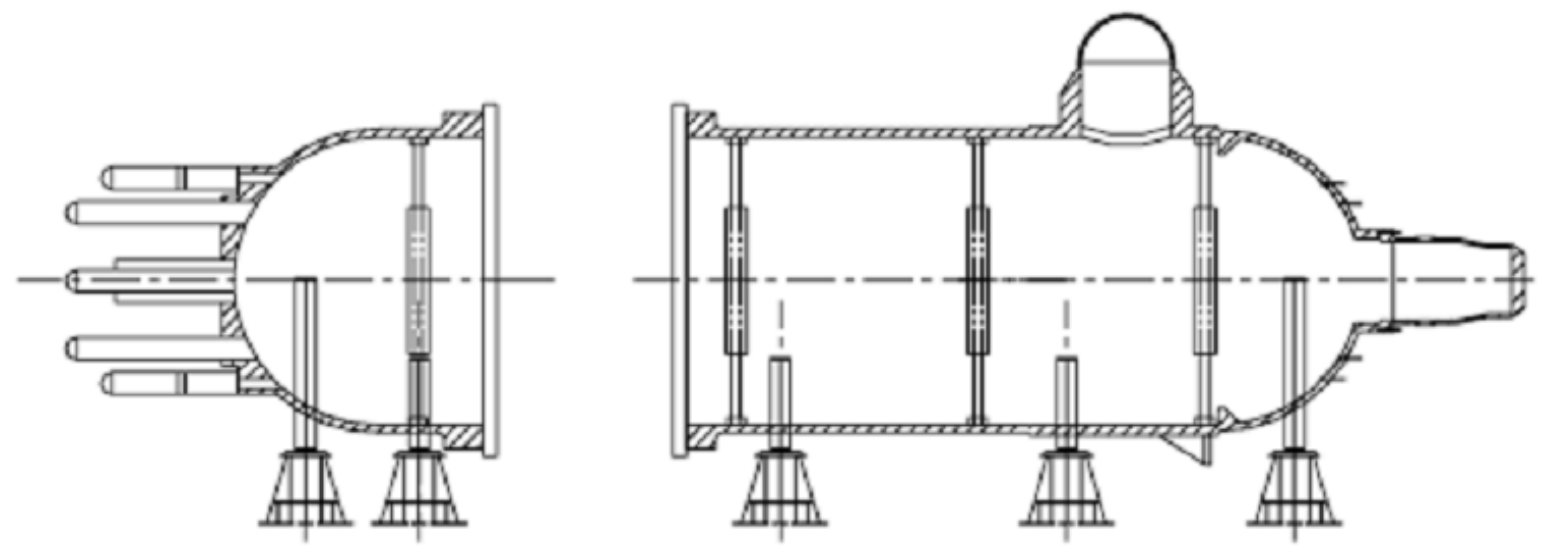

\begin{tabular}{|c|c|c|c|c|c|}
\hline \multicolumn{2}{|c|}{ Component } & $\begin{array}{c}\text { OD } \\
(\mathrm{mm})\end{array}$ & $\begin{array}{c}\text { ID } \\
(\mathrm{mm})\end{array}$ & $\begin{array}{c}\text { Height } \\
(\mathrm{mm})\end{array}$ & $\begin{array}{c}\text { Weight } \\
\text { (ton) }\end{array}$ \\
\hline \multirow{3}{*}{ RV } & Head & $8,420.1$ & $7,226.3$ & $10,207.5$ & $435^{*}$ \\
\cline { 2 - 6 } & RPV & $8,420.1$ & $7,226.3$ & $21,008.3$ & $924^{*}$ \\
\cline { 2 - 6 } & Total & $8,420.1$ & $7,226.3$ & $31,215.8$ & 1,364 \\
\hline \multicolumn{4}{|l}{ * The weight of stud and gasket is excluded. (But it is included in total weigh.) } \\
\hline
\end{tabular}

Figure 8. Reactor pressure vessel-the largest vessel anticipated to be used in the HTGR. [General Atomics 911118,"RPV and IHX Pressure Vessel Alternatives Study Report, April 2008"] 


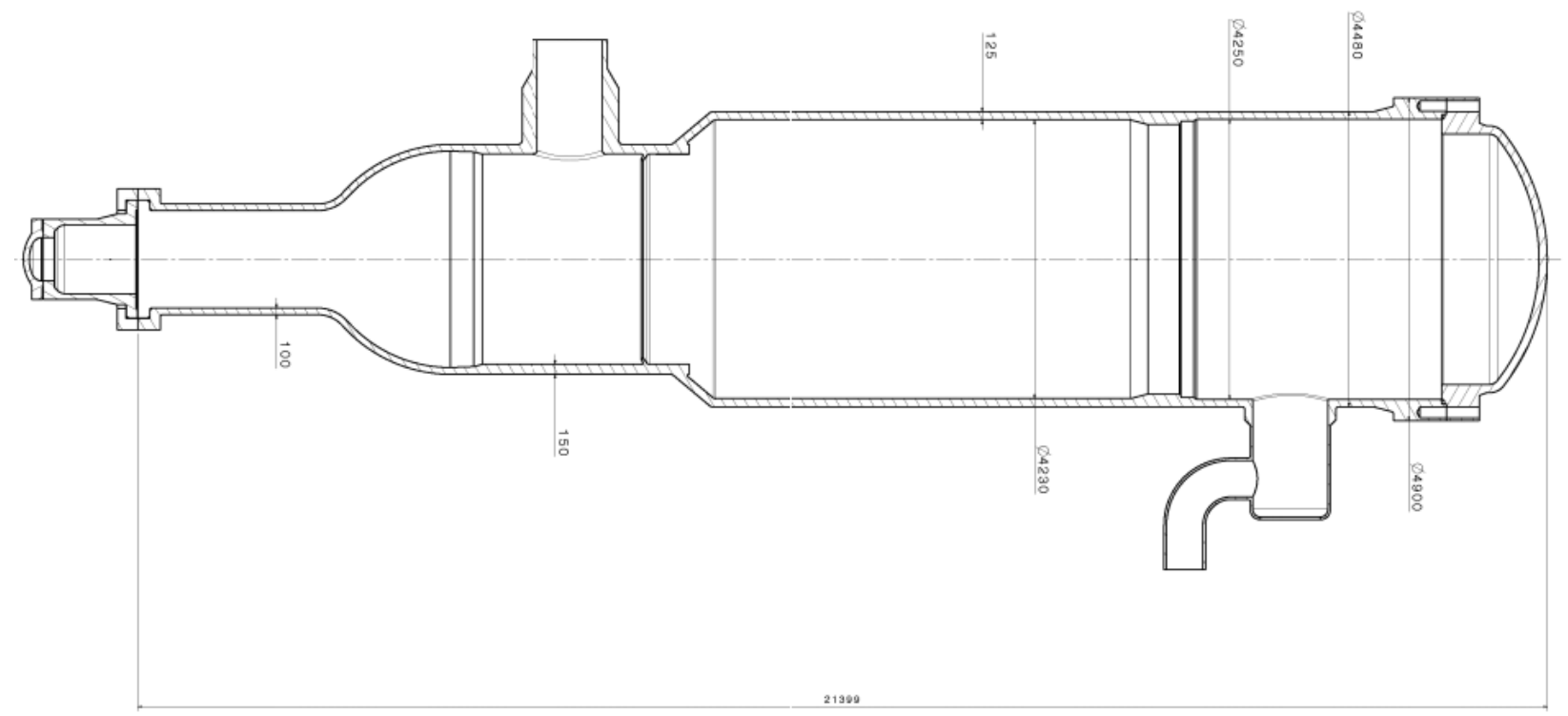

Figure 9. A Typical heat transport system vessel. [AREVA, 12-9076324-001 RPV and IHX Ves Alt_INL.pdf]

As shown the reactor pressure vessel will be shipped in two pieces whereas the heat transport system vessel will be shipped in one piece.

At the time of this writing, Waterford-3 is preparing for reactor vessel head and steam generator replacement outages. The largest components to be handled in these outages are the steam generators with overall weights $>500$ tons. The steam generators will be shipped by barge to a landing on the river in front of the Waterford site. Large mobile cranes will lift the steam generators from the barge and transport them to the containment access up a special ramp constructed up and over the river levee. A similar arrangement would be used to transport the HTGR reactor pressure vessels and heat transport system vessels to the site. These vessels would be fabricated elsewhere with access to waterways that connect with the Mississippi river. The vessels would be shipped by barge to the landing at the Waterford-3 site and carried to the HTGR site from the landing using a mobile crane and ramp up and over the levee.

The Waterford site is also accessible via major highways and railroads. These will be used to transport other components such as helium circulators, the core internals, steam turbine generator shells, turbine stationary blading and rotors, generator stator and rotors, feedwater heaters, and condenser tube assemblies.

An onsite concrete plant will be constructed similar to that used for construction of Waterford-3 and all materials for concrete production as well as other materials of construction will be shipped in by truck and rail.

The successful construction of Waterford-3 provides confidence that there is sufficient access, local infrastructure, and support to construct the HTGR Plant. 


\section{POTENTIAL ENERGY OFF-TAKERS}

\subsection{General}

Figure 10 (reproduced from the Waterford-3 Final Safety Analysis Report) shows the major industrial facilities and oil and gas fields within 5 miles of the Waterford-3 plant. It was assumed in assessing the potential for supplying energy to each of these facilities that (1) the facility needed to be on the same side of the Mississippi river as the Waterford site and (2) the facility consumes steam and/or electricity as part of the operation of the facility. As shown in Figure 3, there are five industrial facilities on the south side of the Mississippi river and east of the Waterford site that have the potential to fit both criteria. However, review of actual energy consumption as summarized in reports to DOE/EIA on Forms 923 and 875 show that only the Union Carbide and the Occidental Chemical Taft Cogeneration plants have sufficient energy capacities and consumption to be considered viable off-takers of energy from the HTGR plant.

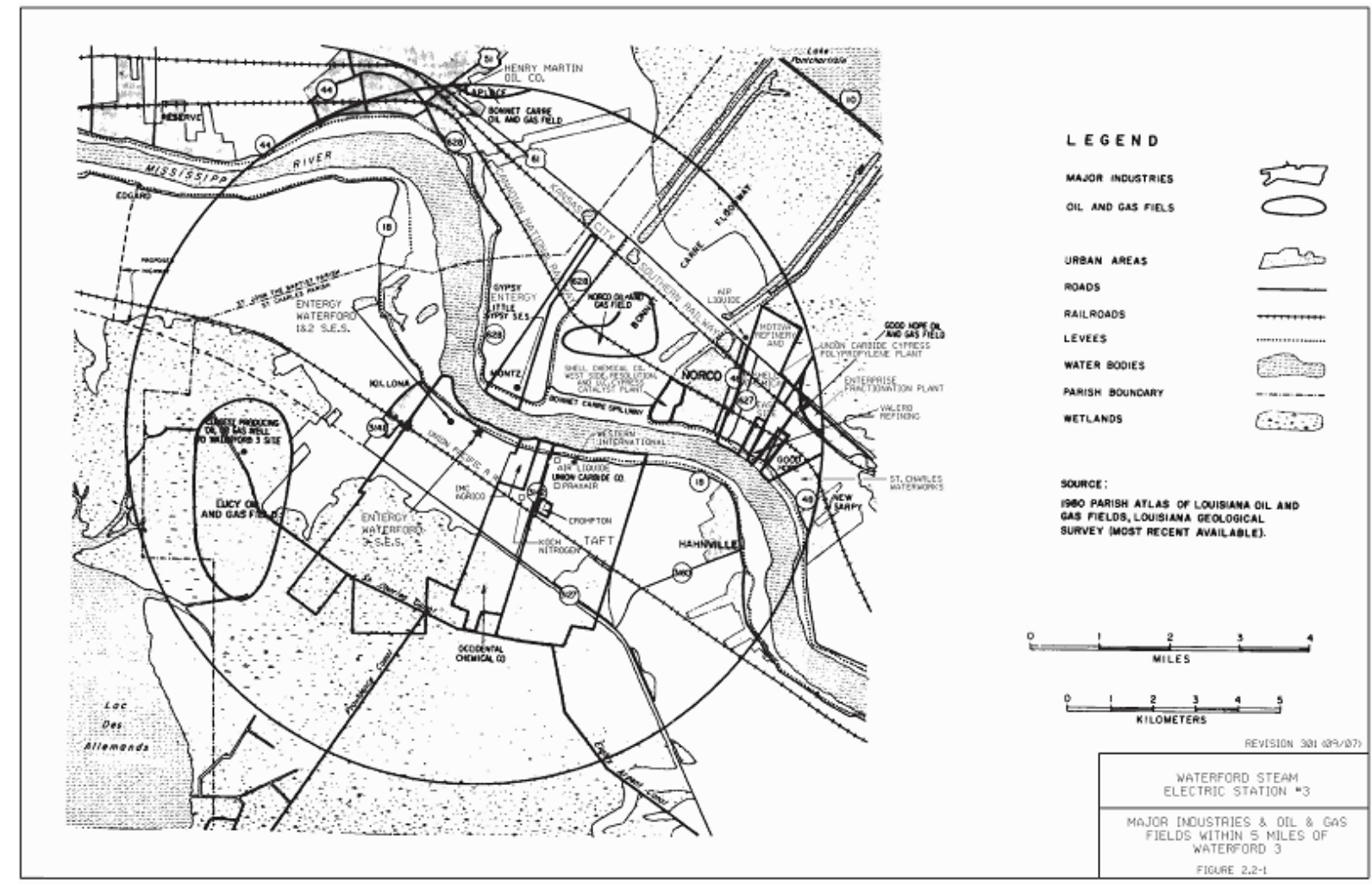

Figure 10. Major industrial facilities located within 5 miles of Waterford-3 nuclear power plant.

\subsection{Union Carbide}

Union Carbide, a wholly owned subsidiary of The Dow Chemical Company, is a petrochemical facility processing a wide range of chemical products. Discussions with Dow personnel determined that the current general plant energy requirements are supplied by two Westinghouse 501D5A gas turbine combined cycle (GTCC) units including a noncondensing steam turbine generator, two package boilers, and a condensing steam turbine generator. These units supply electricity and steam that is distributed to 600,200 , and $75 \mathrm{lb}$ headers in the chemical processing plant. Based on EIA data extracted from facility, EIA-Form-923 reports the energy supplied by the two GTCC units and the condensing steam turbine generator in 2009 and 2010 included steam and electricity as shown in Table 1. 
Table 1. Dow Union Carbide steam and electricity production-2009 and 2010.

\begin{tabular}{|c|c|c|c|c|c|c|c|c|c|c|c|c|c|c|c|}
\hline Type & Location & $\begin{array}{c}\text { Principal } \\
\text { Fuel }\end{array}$ & $\begin{array}{c}\text { Total } \\
\text { Energy, } \\
\text { MMBtu }\end{array}$ & $\begin{array}{c}\text { Energy to } \\
\text { Generate } \\
\text { Electricity } \\
\text { MMBtu }\end{array}$ & $\begin{array}{c}\text { Percent } \\
\text { Electricity } \\
\text { Generation } \\
\%\end{array}$ & $\begin{array}{c}\text { Net } \\
\text { Electricity } \\
\text { Generation } \\
\text { MWhe } \\
\text { (annual) }\end{array}$ & $\begin{array}{c}\text { Percent } \\
\text { Electricity } \\
\text { Sold Off- } \\
\text { Site, \% }\end{array}$ & $\begin{array}{c}\text { Percent } \\
\text { Electricity } \\
\text { from Off- } \\
\text { Site, \% }\end{array}$ & $\begin{array}{c}\text { Average } \\
\text { Energy } \\
\text { Demand, } \\
\text { Monthly } \\
\text { MWt } \\
\text { Equivalent }\end{array}$ & \begin{tabular}{|c|} 
Peak \\
Energy \\
Demand, \\
Monthly \\
MWt \\
Equivale \\
nt \\
\end{tabular} & $\begin{array}{l}\text { Peak to } \\
\text { Average } \\
\text { Energy } \\
\text { Demand }\end{array}$ & \begin{tabular}{|} 
Peak to \\
Minimum \\
Energy \\
Demand
\end{tabular} & $\begin{array}{c}\text { Operatin } \\
\mathrm{g} \\
\text { Electricit } \\
\mathrm{y} \\
\text { Generato } \\
\mathrm{r} \text { Ratings }\end{array}$ & $\begin{array}{c}\text { Net } \\
\text { Capacity } \\
\text { Factor }\end{array}$ & Year \\
\hline CoGen & LA & NG & $22,562,622$ & $15,175,000$ & $67 \%$ & $1,359,915$ & $17.1 \%$ & $5.0 \%$ & 794.57 & 864.04 & 1.09 & 1.20 & 334 & $51 \%$ & 2009 \\
\hline & & & $23,828,457$ & $19,625,826$ & $82 \%$ & $1,758,778$ & \multicolumn{2}{|c|}{ Not Available } & 797.43 & 943.95 & 1.18 & \multicolumn{3}{|c|}{1.77 ot Available } & 2010 \\
\hline
\end{tabular}

Data supplied to INL by Dow personnel indicate that average steam consumption of the plant is in the range of 1.5 million $\mathrm{lb} /$ hour and peak demand is in the range of 1.8 million $\mathrm{lb} /$ hour; equivalent to $\sim 680 \mathrm{MW}(\mathrm{t})$. Review of Table 1 shows that the quantity of steam supplied by the GTCC's is in the range of 25 to $40 \%$ of the average steam produced. The remainder is supplied by the two package boilers; each with a rating of $250,000 \mathrm{lb} /$ hour. As shown in Table 1, the majority of the electricity generated by the two GTCC plants and the condensing steam turbine is consumed on site; less than $20 \%$ was sold offsite in 2009 , and 5\% was obtained from the grid (2010 data will not be available until later in 2011).

For the purposes of sizing the HTGR plant, the following characteristics of the Union Carbide energy needs and supply were applied:

Electricity (Based on EIA data):

- Average demand $220 \mathrm{MW}(\mathrm{e})$

- $\quad$ Peak demand $260 \mathrm{MW}(\mathrm{e})$

- Installed Capacity $335 \mathrm{MW}(\mathrm{e})$.

Steam to the processes (Based on data supplied to INL by Dow personnel):

- Average Flowrate 1.50 million $\mathrm{lb} /$ hour

- Peak Flowrate 1.80 million $\mathrm{lb} /$ hour.

INL discussions with Dow personnel indicate that the energy used in the Union Carbide facility may potentially increase in the future as the plant configuration evolves. This could include a demand for additional energy in the form of hot gas in addition to electricity and steam. The modular characteristics of the HTGR plant facilitate adding plant capacity to respond to changing energy needs such as may be experienced at SCO.

\subsection{Taft Cogeneration Plant}

The data shown in Table 2 is for the Taft Cogeneration plant operated by the Occidental Chemical Corporation. This plant supplies steam and electricity to the co-located petro-chemical plant and electricity to the regional utility. Based on the DOE/EIA data in Table 2 for 2009, the petro-chemical plant used about $30 \%$ of the electricity generated. The total electricity generated by the Taft plant in 2010 was $\sim 5.4$ million MW(e)-hr. The plant, therefore, consumed $\sim 1.6$ million MW(e)-hr or $\sim 180 \mathrm{MW}(\mathrm{e})$ on average over the year. The peak to average demand was around $120 \%$ in 2009 and $110 \%$ in 2010 . Using the larger value, the peak demand would be $\sim 220 \mathrm{MW}(\mathrm{e})$. The steam consumption averages $\sim 500,000 \mathrm{lb} /$ hour and is fed to a $170 \mathrm{lb}$ steam header for use in the plant processes. This supply has a rating of $\sim 170 \mathrm{MW}(\mathrm{t})$. For analysis purposes, it was assumed that the petro-chemical plant peak to average steam demand is similar to that for the Union Carbide plant, resulting in an assumed 700,000 lb/hour peak demand; $230 \mathrm{MW}(\mathrm{t})$. 
Table 2. Taft cogeneration energy consumption and generation-2009 and 2010.

\begin{tabular}{|c|c|c|c|c|c|c|c|c|c|c|c|c|c|c|c|}
\hline Type & Location & $\begin{array}{c}\text { Principal } \\
\text { Fuel }\end{array}$ & $\begin{array}{l}\text { Total } \\
\text { Energy, } \\
\text { MMBtu }\end{array}$ & $\begin{array}{c}\text { Energy to } \\
\text { Generate } \\
\text { Electricity } \\
\text { MMBtu }\end{array}$ & \begin{tabular}{|c|} 
Percent \\
Electricity \\
Generation \\
$\%$
\end{tabular} & \begin{tabular}{|c|} 
Net \\
Electricity \\
Generation \\
MWhe \\
(annual)
\end{tabular} & $\begin{array}{c}\text { Percent } \\
\text { Electricity } \\
\text { Sold Off- } \\
\text { Site, \% }\end{array}$ & $\begin{array}{c}\text { Percent } \\
\text { Electricity } \\
\text { from Off- } \\
\text { Site, \% }\end{array}$ & $\begin{array}{c}\text { Average } \\
\text { Energy } \\
\text { Demand, } \\
\text { Monthly } \\
\text { MWt } \\
\text { Equivalent }\end{array}$ & \begin{tabular}{|c|} 
Peak \\
Energy \\
Demand, \\
Monthly \\
MWt \\
Equivale \\
nt \\
\end{tabular} & $\begin{array}{l}\text { Peak to } \\
\text { Average } \\
\text { Energy } \\
\text { Demand }\end{array}$ & $\begin{array}{l}\text { Peak to } \\
\text { Minimum } \\
\text { Energy } \\
\text { Demand }\end{array}$ & $\begin{array}{c}\text { Operating } \\
\text { Electricity } \\
\text { Generator } \\
\text { Ratings }\end{array}$ & $\begin{array}{c}\text { Net } \\
\text { Capacity } \\
\text { Factor }\end{array}$ & Year \\
\hline CoGen & LA & NG & $34,911,384$ & $32,702,872$ & $94 \%$ & $4,462,663$ & $68.5 \%$ & $0.0 \%$ & 1159.23 & 1413.64 & 1.22 & 3.26 & 894 & $59 \%$ & 2009 \\
\hline & & & $40,275,592$ & $39,230,929$ & $97 \%$ & $5,357,852$ & \multicolumn{2}{|c|}{ Not Available } & 1369.16 & 1540.82 & 1.13 & 1.30 & \multicolumn{2}{|c|}{ Not Available } & 2010 \\
\hline
\end{tabular}

For the purposes of sizing the HTGR plant the following characteristics of the Taft plant were applied:

Electricity:

- Peak demand $220 \mathrm{MW}(\mathrm{e})$

- Installed Capacity 895 MW(e).

Steam to the processes:

- Average Flowrate 500,000 lb/hour

- Peak Flowrate $700,000 \mathrm{lb} /$ hour.

\subsection{Greenhouse Gas Emissions}

The data of Tables 1 and 2 show that Union Carbide and the Taft Cogeneration Plants consumed $\sim 64$ million MMBtu of energy in 2010. The majority of this energy came from the burning of natural gas. At $117 \mathrm{lb} \mathrm{CO}_{2} / \mathrm{MMBtu}$ of natural gas combustion this resulted in $\sim 3.3$ million metric tons of $\mathrm{CO}_{2}$ emissions in 2010. As a non-emitting source of energy, the application of the HTGR technology as the energy source would eliminate these emissions.

\subsection{HTGR Plant Rating Alternatives}

For the purposes of evaluation, two alternatives were developed in sizing the HTGR plant for the Waterford site; one alternative supplies only the specific energy needs of the Union Carbide and Occidental Chemical Corporation plants, the other replicates an estimated capacity of the energy supplies of both sites. In the former case (designated as Alt 1) the plant is sized to supply the total of the peak demands for the two plants. An extra HTGR module is also included in the plant design to ensure 100\% availability during HTGR plant refueling and maintenance outages. This provides some extra electrical capacity available for sale to the regional grid when all modules are in operation.

The latter case (designated as Alt 2) has electrical and steam capacity equivalent to an estimated total capacity of the energy supplies of both plants. The capacity of the electrical supplies is available from EIA data as shown above. The capacities for steam production are not available from publically available data. Accordingly, the estimate of steam capacity assumes that it is $15 \%$ higher than the peak demand (a total of 2.9 million $\mathrm{lb}$ /hour derived from the 2.5 million $\mathrm{lb} /$ hour peak demand cited previously). Because the electrical capacity of this plant is much higher than the peak demand for both facilities, a significant amount of electricity would be available for sale to the grid. In this alternative, the industrial plant energy needs can be met $100 \%$ of the time by reducing the amount of capacity dedicated to supplying electricity to the regional grid during HTGR module refueling and maintenance outages. The specific characteristics of these two plant alternatives are summarized in Table 3. 
Table 3. Two HTGR plant alternative steam \& electrical supply ratings.

\begin{tabular}{|l|l|l|}
\hline \multicolumn{1}{|c|}{ Item } & \multicolumn{1}{|c|}{$\begin{array}{c}\text { Alt 1: } 100 \% \text { of Current Energy } \\
\text { Consumption }\end{array}$} & \multicolumn{1}{|c|}{$\begin{array}{c}\text { Alt 2: } 100 \% \text { of Installed } \\
\text { Capacity }\end{array}$} \\
\hline $\begin{array}{l}\text { Steam supply, lb/hour } \\
\text { MW(t) }\end{array}$ & $2,500,000$ & $\begin{array}{l}2,900,000 \\
1,060\end{array}$ \\
\hline Electrical rating, MW(e) & 910 & 480 to processes \\
& 480 to processes & 750 to grid \\
\hline
\end{tabular}

Section 5 discusses the plant designs, configurations, and siting of the HTGR plant for these two alternatives. 


\section{NOTIONAL HTGR PLANT DESIGN}

\subsection{HTGR Rating}

Figure 11 shows the NHSS and power conversion conceptual relationship that was used to size the HTGR cogeneration plant, develop the layouts on the Waterford site, and perform the economic evaluations. This concept applies to both alternative plant ratings. The implementations of the alternatives differ in the ratings of the NHSS modules, number of NHSS modules, and number of steam turbine generators. Because the HTGR operates at high temperatures, the steam conditions from the NHSS are similar to the superheated steam from a conventional gas or coal fired subcritical boiler; 2,400 psia, $1000^{\circ} \mathrm{F}$. The steam turbine generators operate, therefore, at $3,600 \mathrm{rpm}$ in a conventional subcritical Rankine multi-extraction reheat cycle. This distinguishes the HTGR plant from the LWR power conversion cycle, which operates at lower pressure saturated or near saturated steam conditions and a larger 1,800 rpm turbine generator. The net efficiency of the HTGR cycle is therefore higher (in the range of $40 \%$ ) than the LWR cycle (in the range of $30 \%$ ).

\section{NUCLEAR HEAT SUPPLY}

SYSTEMS

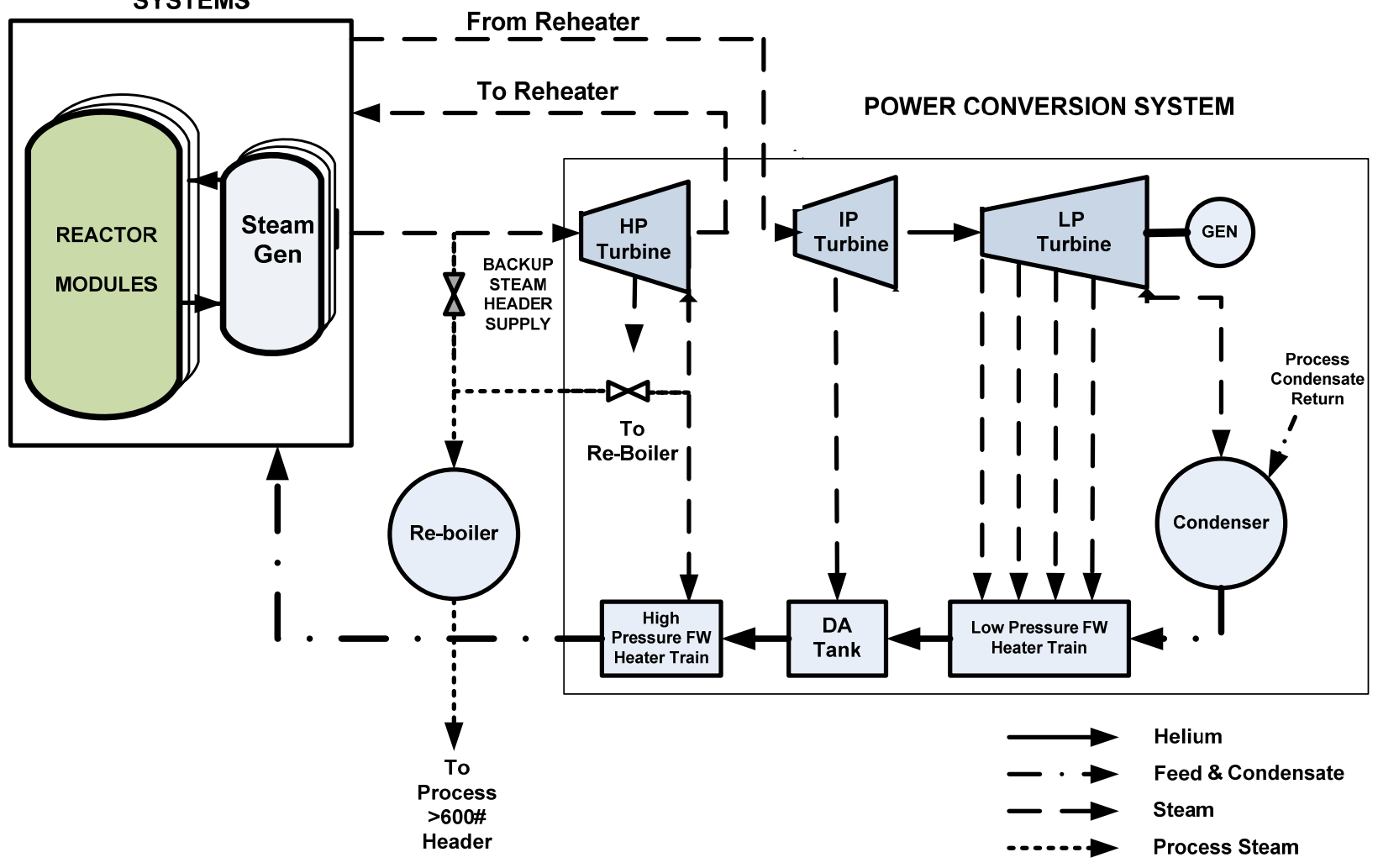

Figure 11. Waterford HTGR cogeneration plant.

The cycle shown in Figure 11 also shows steam supplied to the industrial process in a single header at a nominal pressure $>600 \mathrm{lb}$. This header would then be used to supply the industrial processes at required pressures using let-down valves or other mechanisms such as back-pressure turbines, depending on the process. The steam supplied to the main header is generated in a reboiler supplied with extraction steam from the high pressure end of the turbine cycle. This provides complete separation of the steam supplied to the industrial plants from that supplied by the HTGR steam generator, and ensures that the process steam will not contain any radionuclides from the nuclear process. It also reduces the chemistry 
requirements on condensate returned to the HTGR plant. Sending the steam to the industrial plants in a single high pressure header reduces the complexity of piping and valving that would be required to transfer steam at multiple pressures.

Scoping analyses were performed to establish the plant ratings and number of principal components required to satisfy the energy requirements of the two alternatives summarized in Table 3 . The results of those analyses are summarized in Table $4,{ }^{\mathrm{d}}$ which provides the number of NHSS modules for module ratings of 350 and $600 \mathrm{MW}(\mathrm{t})$. These are NHSS module designs for which design information is currently available.

Table 4. Summary of alternative HTGR plant design characteristics.

\begin{tabular}{|l|l|l|}
\hline \multicolumn{1}{|c|}{ Item } & \multicolumn{1}{|c|}{ Alt 1 } & \multicolumn{1}{c|}{ Alt 2 } \\
\hline Plant Total Rating, MW(t) & 2,400 & 3,600 \\
\hline Electrical Rating, MW(e) & 750 & 1,230 \\
\hline Steam Supply, MW(t) & 910 & 1,060 \\
\hline Number of NHSS Modules & $4-600 \mathrm{MW}(\mathrm{t})$ & $\begin{array}{l}6-600 \mathrm{MW}(\mathrm{t}) \\
10-350 \mathrm{MW}(\mathrm{t})\end{array}$ \\
\hline $\begin{array}{l}\text { Number of Steam Turbine } \\
\text { Generators }\end{array}$ & $2-350 \mathrm{MW}(\mathrm{t})$ & $\begin{array}{l}3-410 \mathrm{MW}(\mathrm{e}) \text { each, 600 MW(t) } \\
\text { modules } \\
4-310 \mathrm{MW}(\mathrm{e}) \text { each, 350 MW(t) } \\
\text { modules }\end{array}$ \\
\hline Condenser Load, MW(t) & 660 & 1,330 \\
\hline
\end{tabular}

\subsection{Plant Layout and Configuration}

Figure 12 shows a preconceptual layout of a 4-NHSS module HTGR plant with two steam turbine generators. This layout is based on component and area sizes used by General Atomics in preparing the steam cycle modular helium reactor conceptual design report for DOE. ${ }^{6}$ The following describes the major blocks shown in Figure 12:

- The reactor modules (designated as RB-1, .. in the following figures) include the buried silo in which the reactor and heat transport system are contained, the reactor building, and Reactor cavity cooling system vent stack.

- The Reactor Support Area includes the Operations Control Center, Reactor Service Building, nuclear instrumentation water supply, spent fuel cooling water supply, shutdown cooling water system and the Reactor Auxiliary Building.

- A turbine generator module (designated as TG-1, .. in the following figures) includes the Turbine Generator Building, the steam turbine and generator, and electrical switchgear.

- The Turbine Support Area includes a water treatment system, ECA Warehouse, Tubine Generator Maintenance Building, auxiliary boiler, Standby Power Building, filtered water tank, demineralized water tank, water treatment clarifier, condensate storage, and fuel oil storage.

- Parking and administration include the plant parking area and the Administration Building which contains Engineering.

d. These analyses were performed in Excel file, "Waterford Cogen Plant Scoping Heat Balances." 


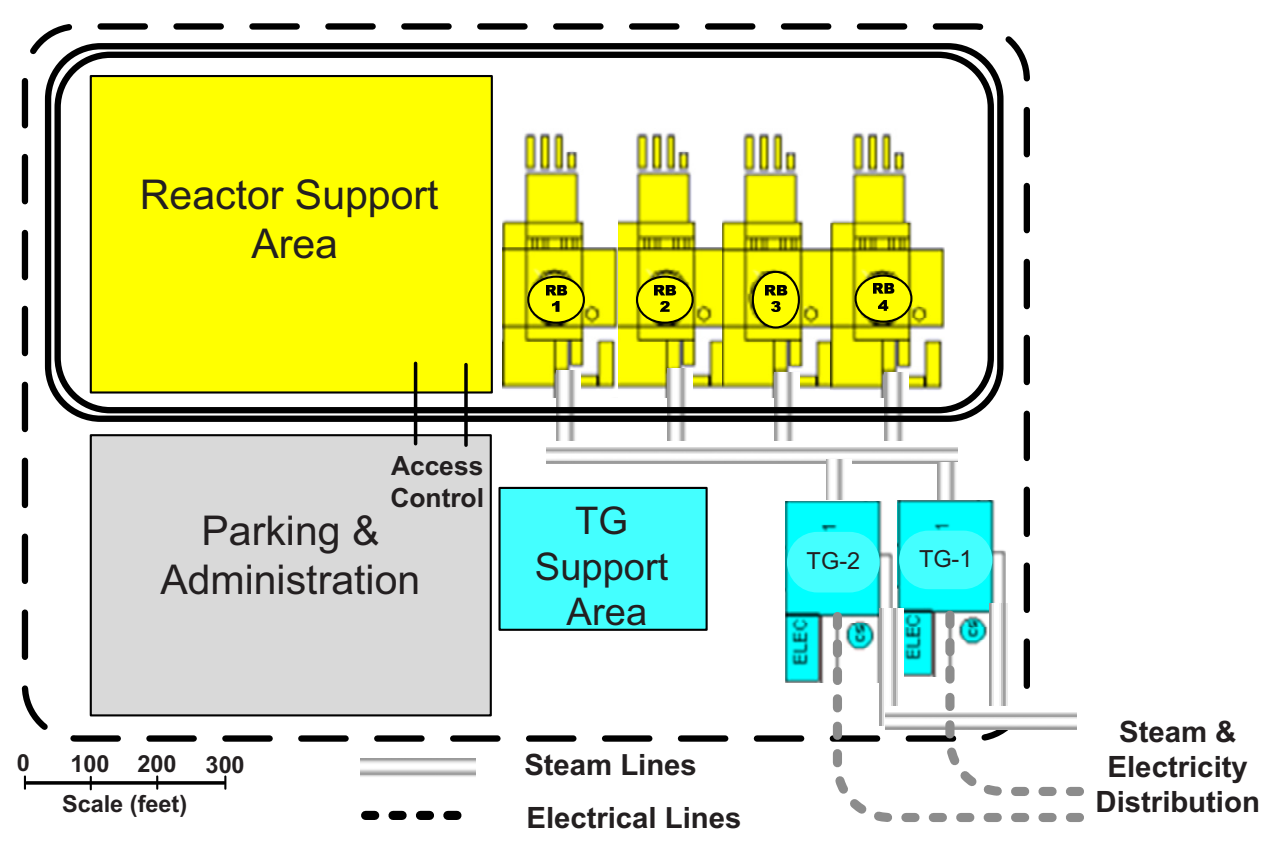

Figure 12. Preconceptual layout of a 4-NHSS module HTGR plant (Visio file:

"Waterford-Eval - Plant Layouts, Variations in the Number of Modules 8-17-11").

The potential variations in the rating of the modules and the plant that could be applied for the co-generation application as described in the preceding section require different layouts of the plant. Three different layouts have been developed and placed on the preferred site location. These include a four-module, a six-module and a 10-module plant layout. The four-module layout accommodates the four $600 \mathrm{MW}(\mathrm{t})$ plant and the four-module layout accommodates the six $350 \mathrm{MW}(\mathrm{t})$ plant for the Alternative 1 plant design. As noted above, these would supply the steam and electricity needs of the potential end users with an additional HTGR module(s) that provides about $250 \mathrm{MW}(\mathrm{e})$ available to sell on the regional grid.

The alternative two-plant design includes a six $600 \mathrm{MW}(\mathrm{t})$ module $(3,600 \mathrm{MW}(\mathrm{t}))$ plant or a 10 $350 \mathrm{MW}(\mathrm{t})$ module $(3,500 \mathrm{MW}(\mathrm{t}))$ plant. These plant designs would essentially duplicate all of the energy supply resources for steam and electricity generation currently in operation at the two potential end-user sites. As shown above, this capacity would permit significant sales of electricity off site and to the regional grid.

Figures 13, 14, and 15 show the four-module, six-module, and 10-module plants located on the preferred site. The yellow line shown on these figures is parallel with and 1,100 ft north of the Texas \& Pacific rail lines.

Referring to Figures 13 and 14, the control rooms have been positioned to be north of the 1,100 $\mathrm{ft}$ line to ensure that the postulated railcar explosion hazard does not require special design features to be accommodated in the design and licensing basis of the plant. The 400 meter EAB of all the reactor NHSS also do not enclose Waterford-3 nor extend beyond the Waterford site boundaries. This is illustrated by the dotted black lines on the figures that show the 400 meter boundaries for the end modules that define the east and west extents of the plant EAB. 


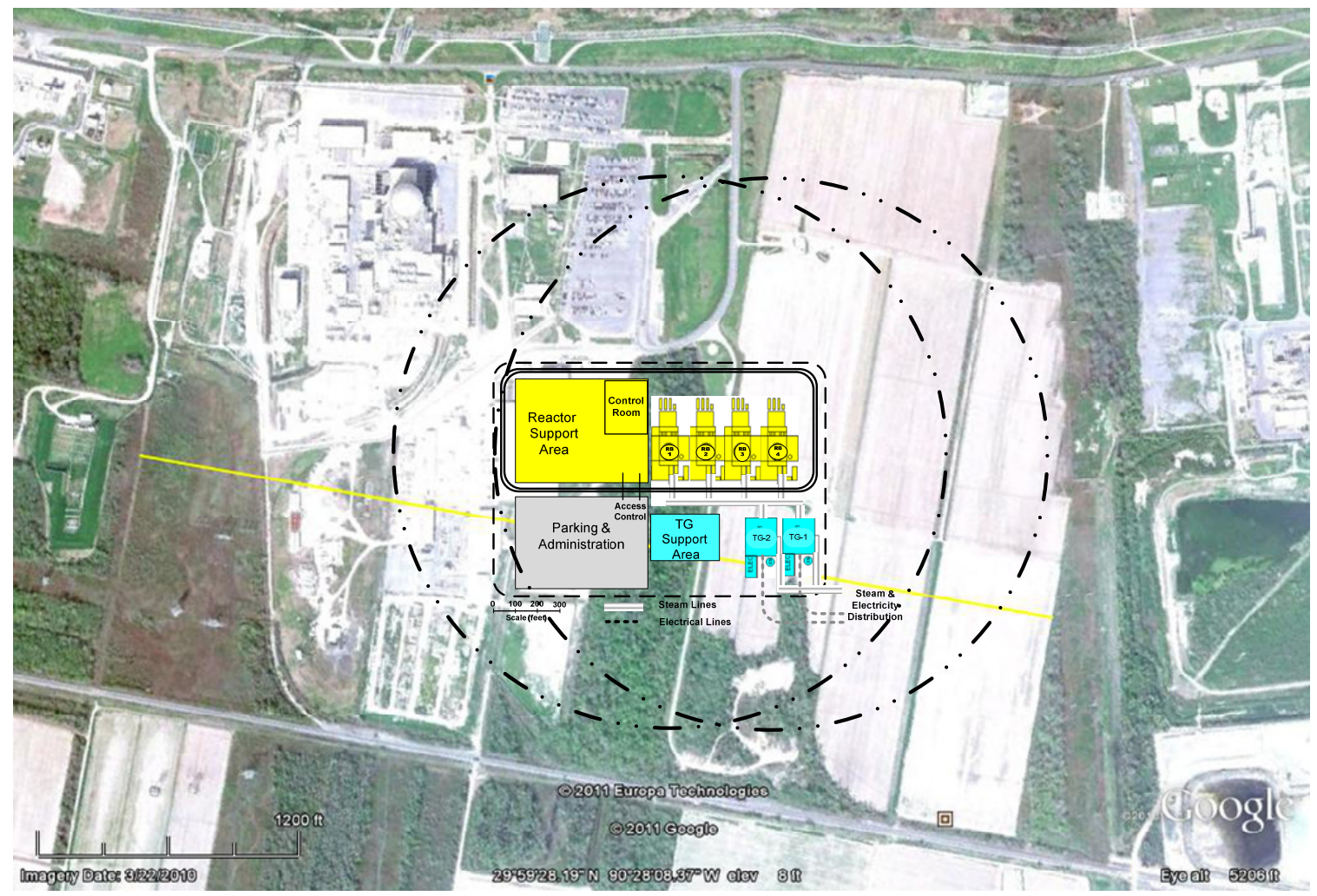

Figure 13. The four-module layout on the preferred location. [Visio file: "Waterford-Eval - Plant Layout"]

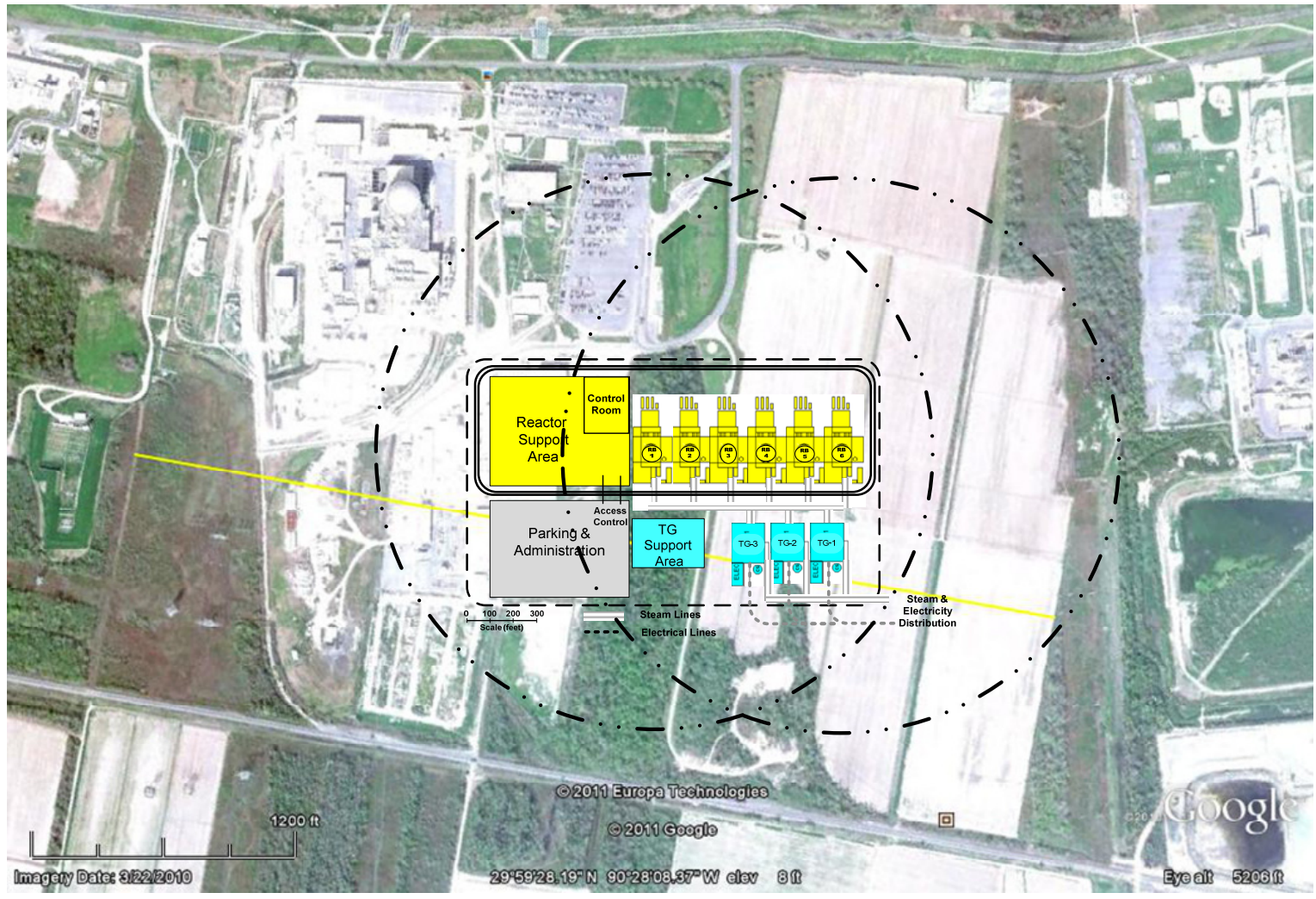

Figure 14. The six-module plant layout on the preferred location. [Visio file: "Waterford-Eval - Plant Layout"] 
Figure 15, shows the 10-module layout selected for this plant size. Two different layouts were considered. One added four more NHSS modules to the east of the six-module layout shown in Figure 14. This was not an acceptable arrangement because the 400 meter EAB for all four of the added NHSS modules cross over the site property line into the east industrial facility. It is not possible to move the full site further west because of interference with high voltage transmission lines that run from Waterford-3 through this area to the high voltage switchyard. It is not judged practical to move those lines to permit siting the HTGR plant in that location. Accordingly, the offset parallel arrangement of the NHSS modules shown in Figure 15 was selected as the most practical. The position of the control room is the same as in the other configurations thereby avoiding special design features to accommodate the postulated railcar explosion hazard.

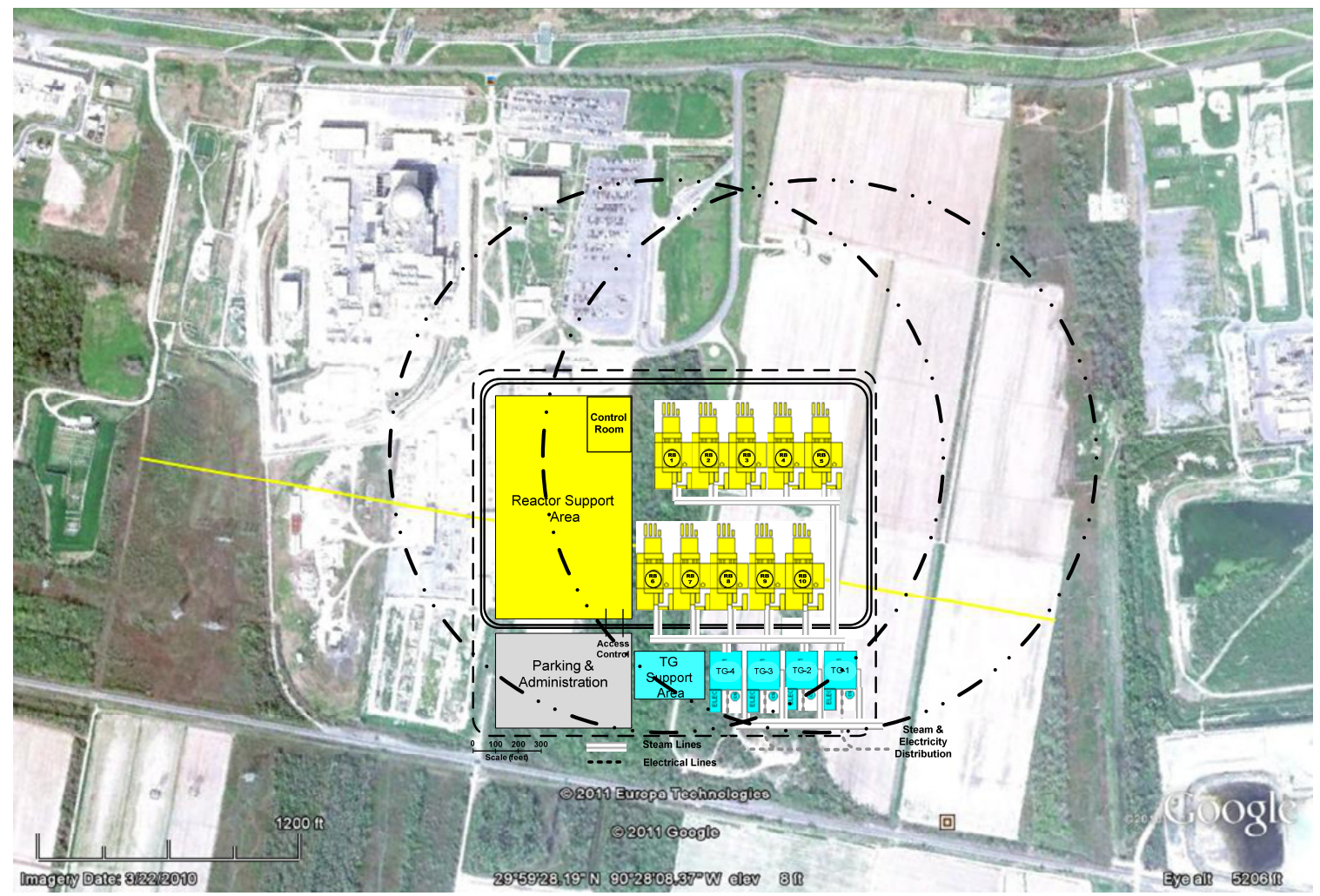

Figure 15. The 10-module layout on the preferred location. [Visio file: "Waterford-Eval - Plant Layout"]

\subsection{HTGR Cogeneration Plant Schedule}

The conceptual schedule for implementing the Waterford HTGR cogeneration plant assumes a mature HTGR design and deployment plan as shown in Figure 16. This schedule assumes that the Cogeneration plant will be implemented using Nth-of-a-kind modules in an optimized deployment. This deployment includes a 6-year period for construction of the first module, which includes 2 years of initial site preparation and major material and component procurements, 4-years for construction of the second module, and 3-year construction periods for all remaining modules. The construction periods are overlapped so that each module starts operation 6 months after the prior module. The length of time required for deployment of all modules depends on the number of modules in the plant. 
HTGR COGEN PLANT DESIGN, CONSTRUCTION, COMMISSIONING AND OPERATION

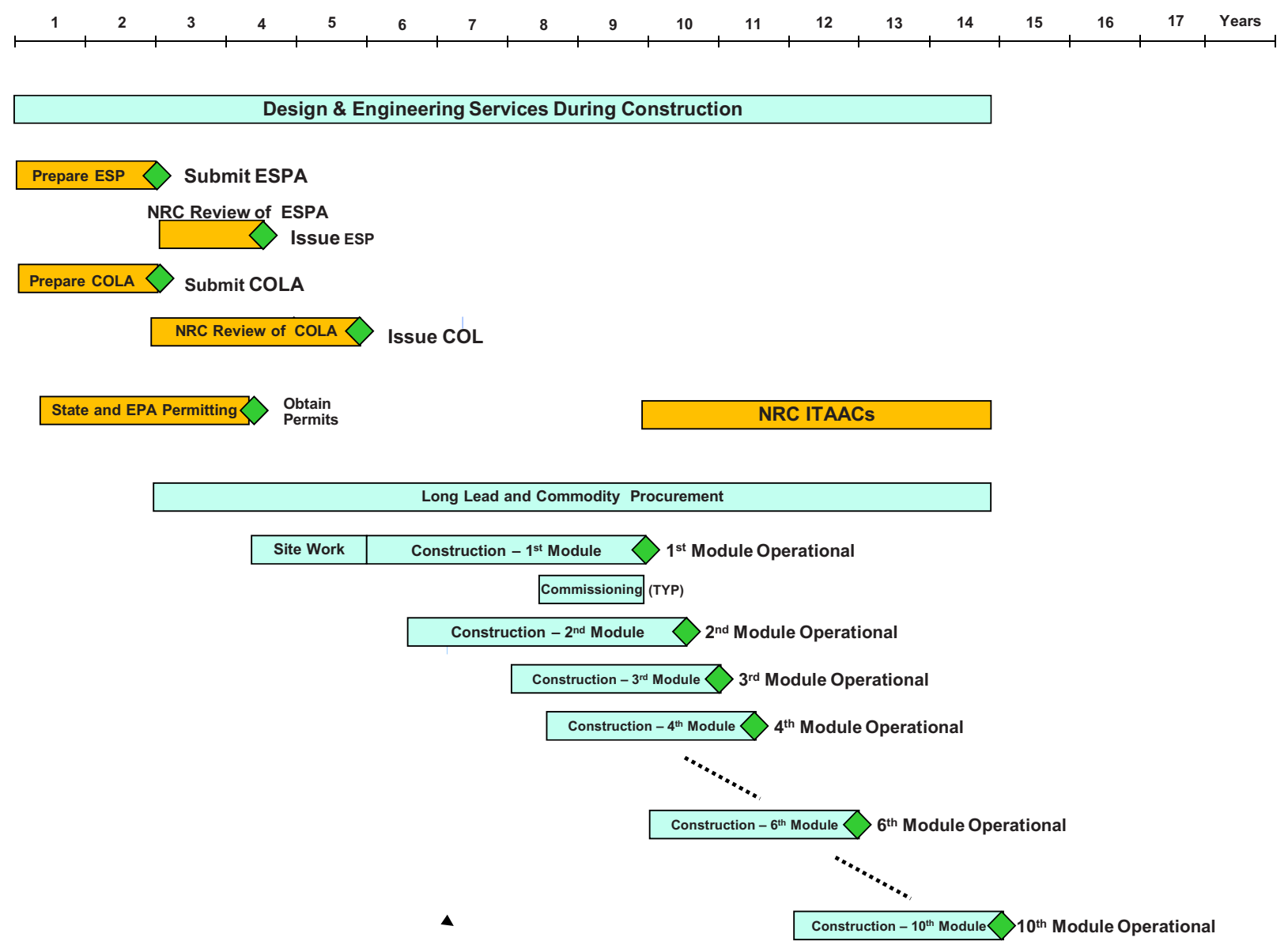

Figure 16. HTGR cogeneration plant deployment schedule.

As shown in Figure 16, there is a 5-year period before the beginning of the first module construction. This period is required for licensing and permitting activities, assuming that a Design Certification and a Reference COL exist for the HTGR plant. It is assumed that the HTGR plant will be licensed by the NRC under 10 CFR 52 with issue of a COL. It is also assumed that an Early Site Permit (ESP) will be obtained. Site preparation work is assumed to start upon receipt of the ESP about 2 years prior to receipt of the COL whereupon full construction of the first module can start. During construction and commissioning of the modules, the NRC will close out open items identified as inspection, testing, and acceptance criteria prior to authorizing initial fuel loading for each module. This process will continue through construction of the final module. As shown, a four-module plant could be in full operation 11 years after the start of the project, with a total construction period of 7 years, including early site preparation The six-module plant adds 1 year to the construction period and total project period. The 10-module plant adds 3 years.

These deployment schedules were assumed in the economic analyses of the three alternative configurations. 


\subsection{Assumed Business Model}

Figure 17 depicts the business model on which the economics are based. The HTGR plant is assumed to be a standalone entity. It is assumed that the owner(s) of the HTGR plant would enter into long term energy supply agreements with the industrial facilities. Similar contracts would be entered into with the regional utilities and others for supply of excess electricity. To achieve the required internal rate of return on equity, these agreements need to have provisions to support the full use of HTGR plant energy at a high capacity factor over the lifetime of the plant. Typically, energy supply contracts will only extend for several years. They will contain clauses for price adjustments over this period, (e.g., to account for inflationary factors) and provisions for continuation. It is important that such contracts between the cogeneration plant and the energy off-takers provide adequate incentives for continuing these contracts over the life of the plant. This is necessary because nuclear plants have high capital costs but very low operating costs. During the period of capital recovery, capital recovery makes up $\sim 70 \%$ of the operating costs. This contrasts with natural gas plants where fuel costs can account for up to $70 \%$ of the operating costs over this period. Accordingly, achieving the required internal rate of return on equity relies on long term operation at near full capacity factors.

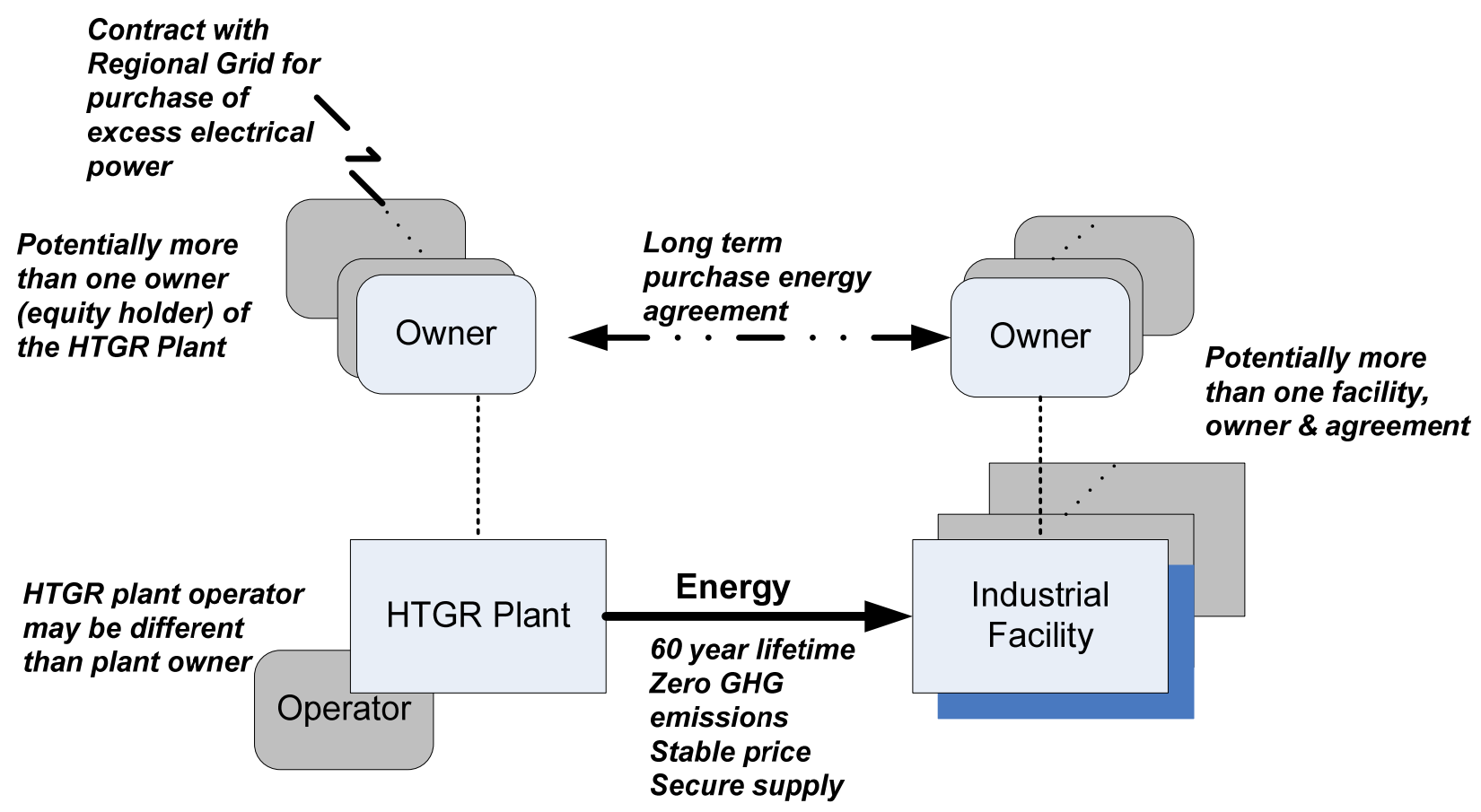

Figure 17. Business model.

\subsection{Costs}

The costs for the HTGR Plant design, licensing, construction, commissioning and operation are based on correlations that account for the total rating of the plant, the reactor outlet temperature of the NHSS modules, the rating of the NHSS modules, the number of steam turbine generators, decommissioning costs, refueling outage costs and scheduled and unscheduled outage costs. ${ }^{7}$ The correlations were developed from specific plant cost estimates for HTGRs developed in the 1980s and 1990s by General Atomics for DOE, during the development of preconceptual designs by the NGNP Project in 2007, as part of updates of costs as the designs and design requirements for the NHSS evolved from discussions with potential end users, and from bottoms up analysis of costs of major components such as large vessels 
The costs for these components in $2010 \$$ are summarized in Table 5. The economic evaluations apply inflation factors over the length of the project. All NHSS costs are based on a reactor outlet temperature of $750^{\circ} \mathrm{C}$.

In reviewing Table 5, note the following:

- The capital costs are in $2009 \$$. The inflation factor accounts for inflation from 2009 to 2010 based on industry Chemical Engineering Plant Cost Index factors (2009-521.9, 2010-550.8).

- A refueling period of 18 months has been assumed so there will be more than one refueling each year for all of these configurations. The annual refueling costs are an average including the cost of replacement cores and the costs for performing the refuelings.

- The plant configurations using $350 \mathrm{MW}(\mathrm{t})$ module ratings have higher per unit costs than those using $600 \mathrm{MW}(\mathrm{t})$ module ratings. Figure 18 compares the costs per $\mathrm{kW}(\mathrm{t})$ of the NHSS modules as a function of the plant rating for module ratings of 200, 350, and $600 \mathrm{MW}(\mathrm{t})$.

Table 5. Summary of HTGR cogeneration plant estimated capital and operating costs (2010\$ unless noted otherwise).

\begin{tabular}{|l|c|c|c|c|}
\hline \multirow{2}{*}{\multicolumn{1}{|c|}{ Item }} & 4-Modules & \multicolumn{2}{|c|}{ 6-Modules } & 10 Modules \\
\cline { 2 - 5 } & $\begin{array}{c}600 \mathrm{MW}(\mathrm{t}) \\
\text { NHSS }\end{array}$ & $\begin{array}{c}600 \mathrm{MW}(\mathrm{t}) \\
\text { NHSS }\end{array}$ & $\begin{array}{c}350 \mathrm{MW}(\mathrm{t}) \\
\text { NHSS }\end{array}$ & $\begin{array}{c}350 \text { MW(t) } \\
\text { NHSS }\end{array}$ \\
\hline $\begin{array}{l}\text { Design, licensing and permitting costs, } \\
\text { construction and engineering services, } \\
\text { owners cost, \$MM* }\end{array}$ & 1,310 & 1,770 & 1,265 & 1,860 \\
\hline NHSS capital cost, \$MM* & & & & \\
\hline Steam turbine generator costs, \$MM* & 1,750 & 2,445 & 1,700 & 2,600 \\
\hline Contingency, \$MM* & 335 & 440 & 300 & 430 \\
\hline Inflation 2009\$ to 2010\$ & 230 & 930 & 655 & 975 \\
\hline \multicolumn{1}{|c|}{ Total Plant Capital Cost, \$MM (2011\$) } & 4,300 & 5,900 & 4,135 & 6,190 \\
\hline Replacement core costs, \$MM & 53 & 53 & 30 & 30 \\
\hline Annual refueling costs, \$MM & 140 & 210 & 125 & 205 \\
\hline $\begin{array}{l}\text { Operating and maintenance costs (exclusive } \\
\text { of replacement cores), \$MM/annum }\end{array}$ & 105 & 140 & 130 & 205 \\
\hline Decommissioning annual payment, \$MM & 11 & 16 & 9 & 15 \\
\hline * 2009\$ & & & & \\
\hline
\end{tabular}




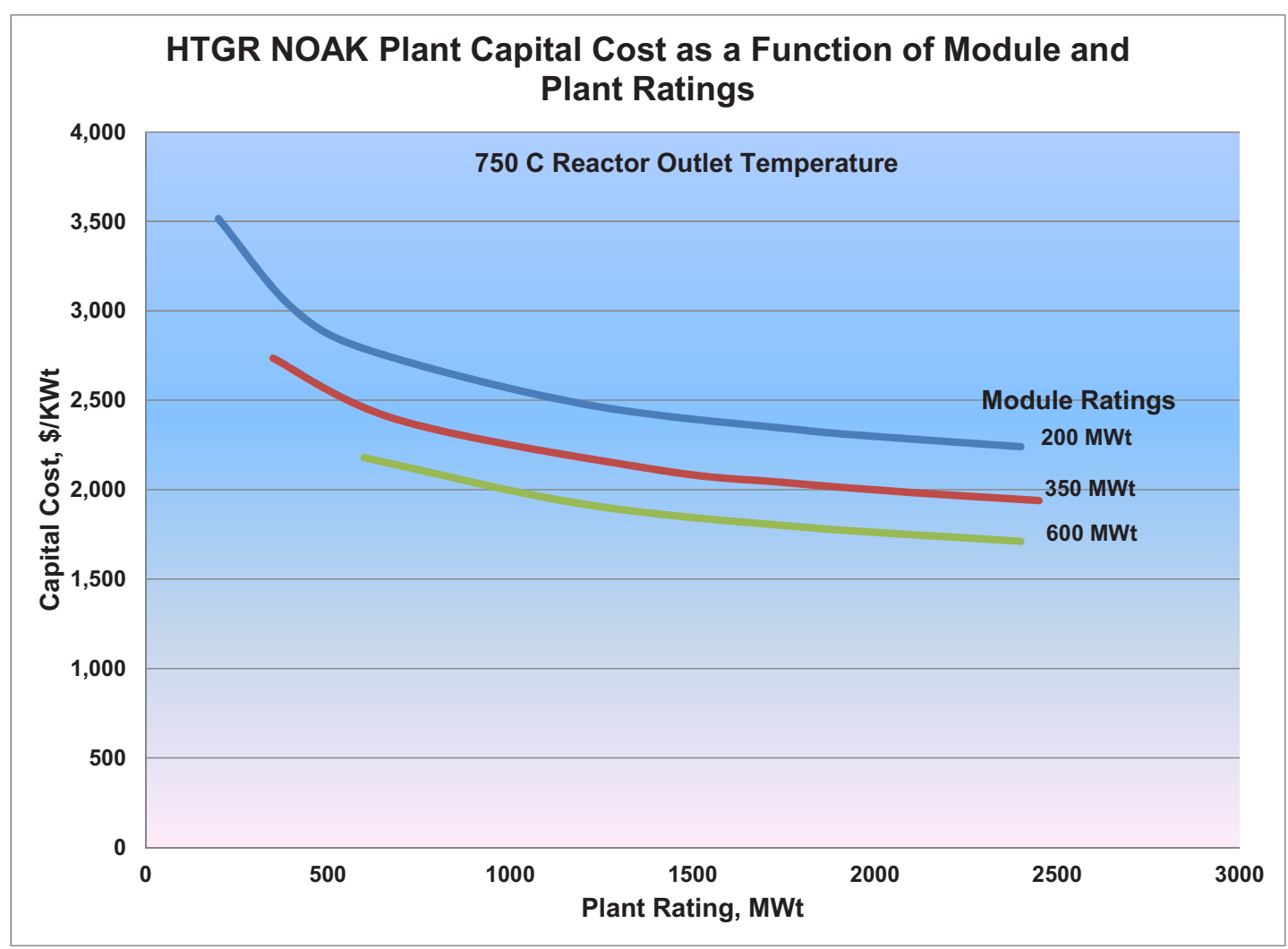

Figure 18. Per unit capital costs versus module and plant rating.

\subsection{Pricing of Energy}

The NGNP Project developed an economics modeling code to support evaluating the economic viability of HTGR integration with industrial processes. ${ }^{8}$ The model is based on discounted cash flow analysis, which includes all capital and operating costs for the HTGR plant and, where applicable, the industrial plant. The model is configured to permit analysis of only the HTGR plant, providing energy in specified forms (e.g., steam, electricity, heat) or an integrated plant including the HTGR as the principal energy supply and the industrial processes producing a specific product(s), (e.g., ammonia, synthetic transportation fuels, hydrogen, bitumen, syncrude). The internal rate of return on owner equity and net present value are the principal parameters of interest calculated by the model.

The model includes high level designs of the plant configuration being analyzed, (e.g. an HTGR plant only or a fully integrated industrial plant) that is used to develop capital and operating costs. In addition to capital and operating costs, model inputs include project schedule, construction schedule and cost profile, financial parameters and project life. The plant capacity factors take into account the staggered commissioning of each module and the periods when the NHSS modules are off-line for refueling and scheduled outages. An additional factor is applied to the capacity factor to account for unscheduled outages.

The model performs the calculation of internal rate of return on owner equity based on discounted cash flow over the life of the project using one of two optional approaches. In one alternative, the prices of the products are adjusted to achieve a required return. In the other the return is calculated for given product prices. For the economic analysis of the Waterford HTGR Cogeneration Plant the former approach is used, (i.e., the prices of steam, electricity and heat supplied to the industrial processes and to the grid are adjusted to achieve a required return). The results of this analysis are summarized below. 
The capital and operating costs for the Cogeneration plant were summarized in the preceding section. Other key parameters of the analysis are summarized in Table 6.

Table 6. Key economic analysis parameters.

\begin{tabular}{|l|l|}
\hline \multicolumn{1}{|c|}{ Item } & \multicolumn{1}{c|}{ Value } \\
\hline Project Start Date & 2015 \\
\hline Total construction time & 6 to 9 years \\
\hline Project Lifetime & 60 years \\
\hline Required Internal Rate of Return on Owner Equity & $10 \%$ \\
\hline Debt to Equity Ratio & $80 \%$ \\
\hline Interest During Construction & $8 \%$ \\
\hline Debt Financing Interest & $8 \%$ \\
\hline Debt Term & 20 years \\
\hline Consolidated Tax Rate & $38.9 \%$ \\
\hline Depreciation & MACRS 15 years \\
\hline Inflation Factor & $3 \%$ \\
\hline Escalation Factor & None \\
\hline
\end{tabular}

The baseline per unit costs for steam, electricity, and heat are calculated in Table 7 for the several configurations considered for the cogeneration plant.

Table 7. Baseline unit costs for steam, electricity, and heat.

\begin{tabular}{|l|c|c|c|c|}
\hline \multirow{2}{*}{\multicolumn{1}{c|}{ Item }} & 4-Modules & \multicolumn{2}{|c|}{ 6-Modules } & 10 Modules \\
\cline { 2 - 5 } & $\begin{array}{c}600 \mathrm{MW}(\mathrm{t}) \\
\text { NHSS }\end{array}$ & $\begin{array}{c}600 \mathrm{MW}(\mathrm{t}) \\
\text { NHSS }\end{array}$ & $\begin{array}{c}350 \mathrm{MW}(\mathrm{t}) \\
\text { NHSS }\end{array}$ & $\begin{array}{c}350 \mathrm{MW}(\mathrm{t}) \\
\text { NHSS }\end{array}$ \\
\hline Electricity, \$/MWhe & 71 & 64 & 82 & 77 \\
\hline Steam, \$/1000 lb & 11 & 10 & 13 & 12 \\
\hline Heat, \$MMBtu & 9 & 8 & 10 & 10 \\
\hline
\end{tabular}

This table shows the effect of the higher $\$ / \mathrm{kW}(\mathrm{t})$ cost for the $350 \mathrm{MW}(\mathrm{t})$ module rating versus that of the $600 \mathrm{MW}(\mathrm{t})$ rating and the benefit of the larger 3,600 MW(t) plant. It should also be noted that the $350 \mathrm{MW}(\mathrm{t})$ module rated plants had less total plant rating than the $600 \mathrm{MW}(\mathrm{t})$ module plants so there was less excess electrical power available for sale to the grid. The results would not have changed much if additional $350 \mathrm{MW}(\mathrm{t})$ modules were added. The results clearly illustrate the economies of scale. For this reason the 3,600 MW(t) (6-600 MW(t) modules) is judged to be the best alternative for this application and is referred to as the HTGR cogeneration plant in the following.

Figure 19 compares the price of electricity and steam from the HTGR Cogeneration plant with historical electricity and steam prices generated from natural gas fired plants as a function of the price of natural gas. A range of electricity and steam prices are shown for the HTGR plant. This range covers variations in internal rate of return on equity from 10 to $15 \%$ (low to high price). As noted on the figure these correlations of electricity and steam price with natural gas price for natural gas fired plants were developed by General Atomics in an HTGR conceptual design report prepared under a cooperative agreement with the DOE.6 As shown, the HTGR plant pricing is comparable to historical prices for natural gas prices in the $\$ 5-1 / 2$ to $\$ 6 / \mathrm{MMBtu}$ range. This indicates that the HTGR plant can be competitive with natural gas fired plants for the conditions evaluated. 


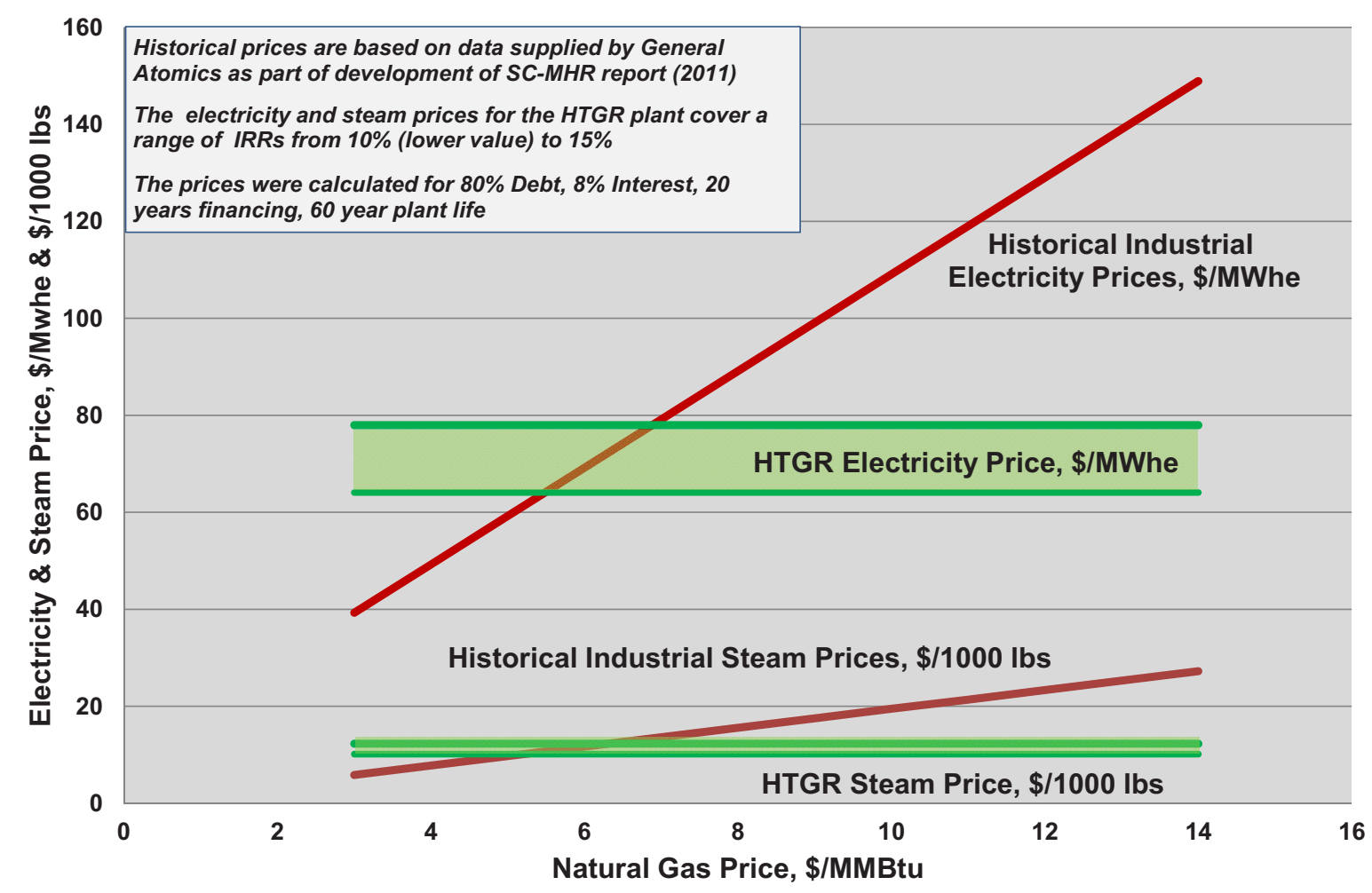

Figure 19. Comparison of HTGR Prices with Natural Gas Plant.

Because of the early development phase of the HTGR plant design, there is large uncertainty in the capital and operating costs for the plant and the financial factors that will be in place when the plant is deployed. The following summarizes the results of additional analyses that were performed to evaluate the impact of these uncertainties in the cost and financial factors on the range of potential product pricing for the HTGR cogeneration plant.

Figures 20 and 21 present tornado charts showing the impact of variations in key factors on the price of electricity and steam from the HTGR cogeneration plant. The required internal rate of return on equity and the cost of the plant have the most influence on the required pricing of electricity and steam. These tornado charts illustrate the influence of individual parameters on the necessary pricing to meet the required internal rate of return. It is not appropriate to combine the effects of multiple parametric variations shown on these charts. Instead, Figures 22 and 23 show the combined effects of these variations in the form of probability distributions for electricity, steam, and heat prices. These charts were developed using a 10,000 step Monte Carlo Simulation applying triangular distributions over the extremes identified for each parameter in Figures 20 and 21. Figures 22 and 23 also show the relevant statistics for each price. Note that the mean values are generally higher than the baseline values for electricity and steam supplied from the HTGR plant. Referring to Figures 20 and 21, this is because the effects of the largest contributors to uncertainty — required IRR and plant cost — tend to bias the distribution to higher pricing. In any event, the differences in the statistical means and the baseline values are not significant. The relatively large standard deviations reflect the large uncertainty in the values of the key parameters. As the design of the HTGR evolves, these uncertainties will be reduced and more confidence developed in the economics of its application to this and other industrial applications. 


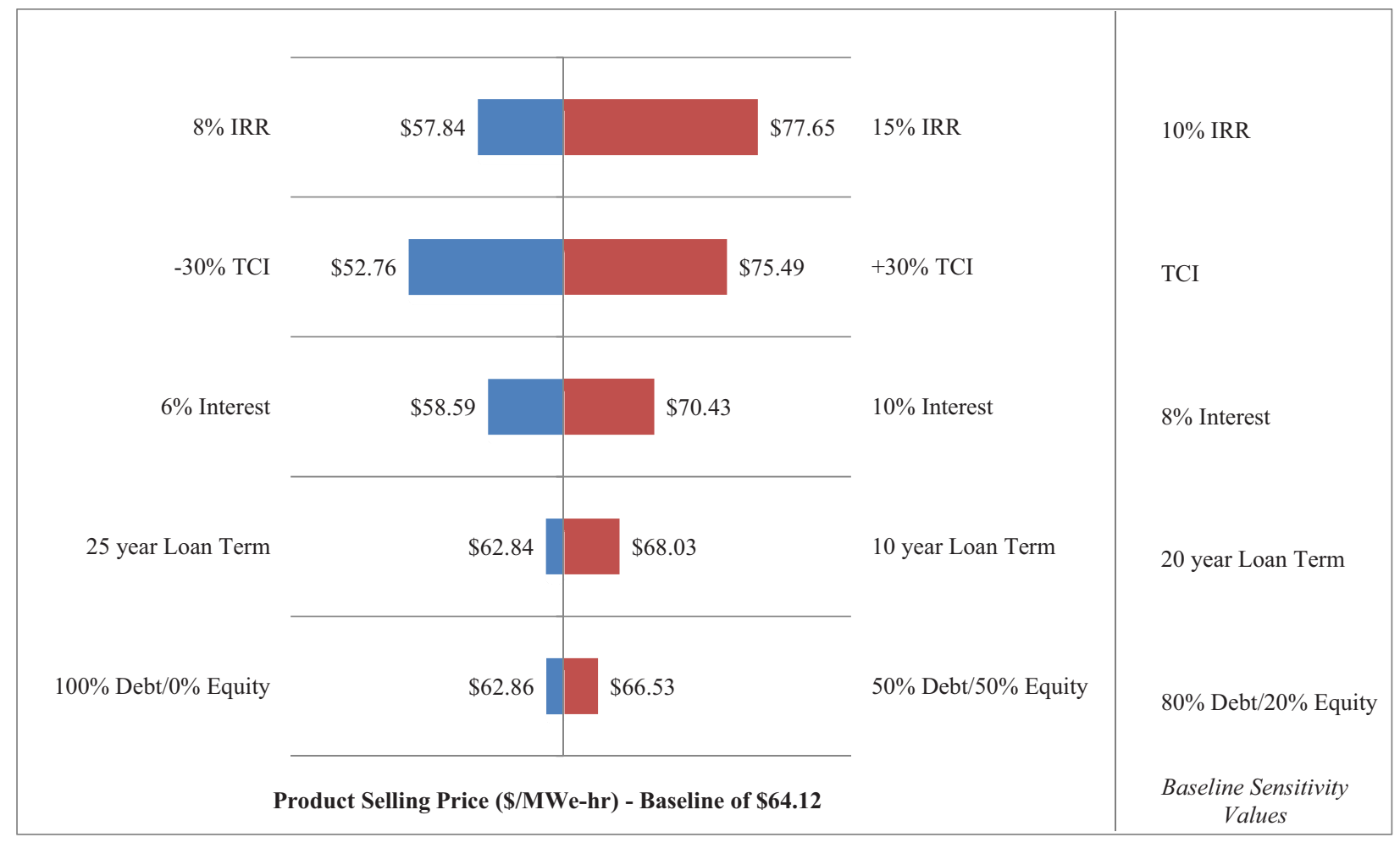

Figure 20. Effect of variations in key economic parameters on the price of electricity.

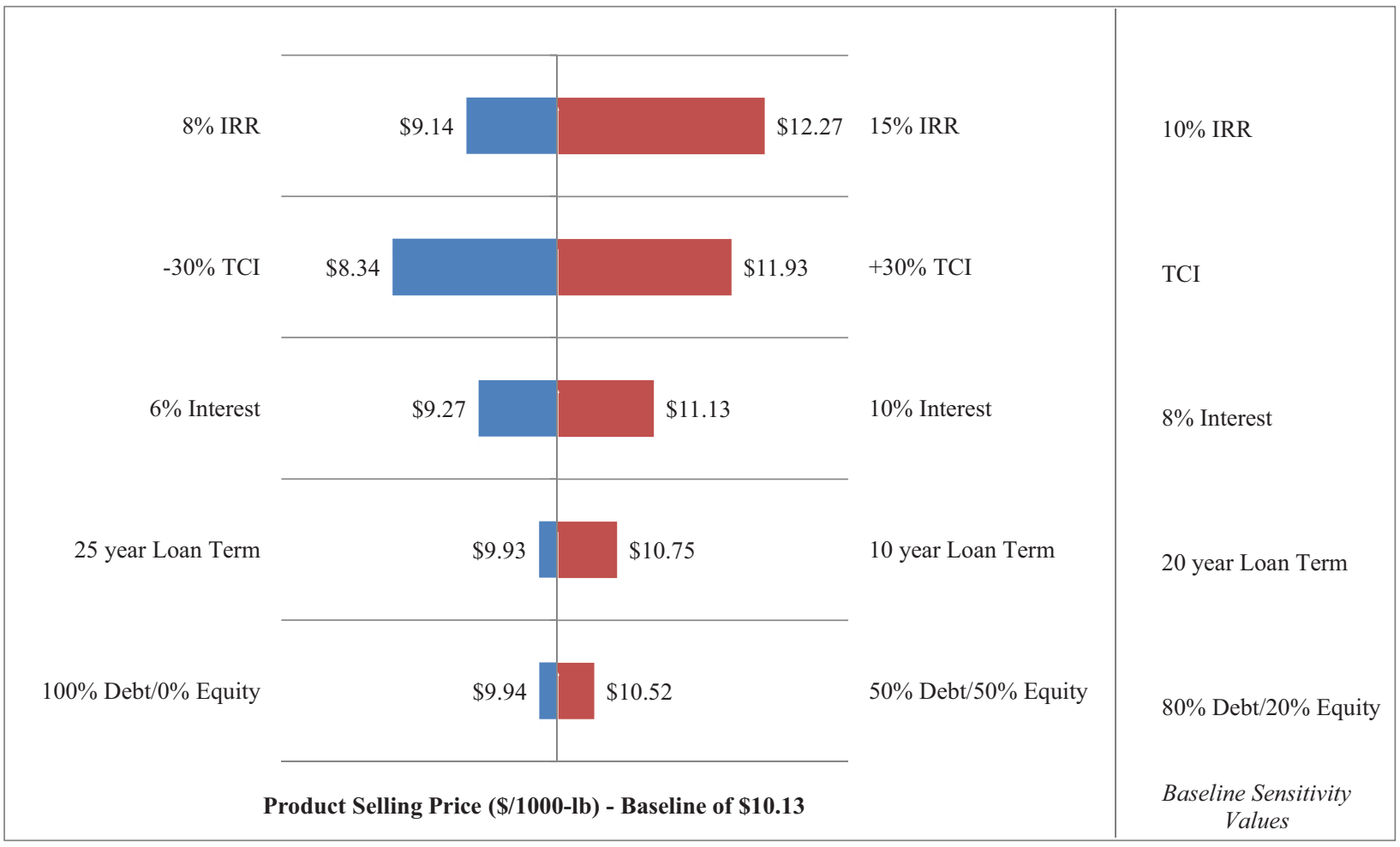

Figure 21. Effect of variations in key economic parameters on the price of steam. 
Summary:

Entire range is from $\$ 42.61$ to $\$ 110.17$

Base case is $\$ 64.12$

After 10,000 trials, the std. error of the mean is $\$ 0.10$

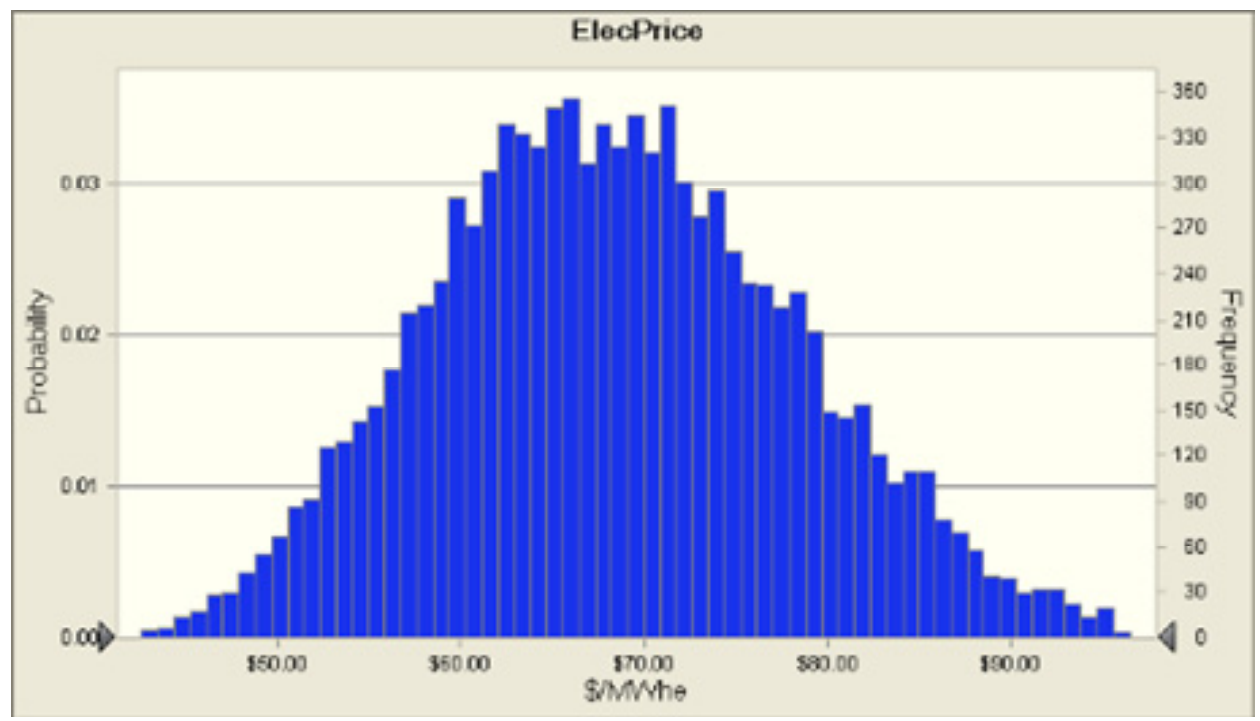

Statistics:

Trials

Forecast values

Mean

10,000

Median

$\$ 68.54$

Mode

$\$ 68.07$

Standard Deviation

$\$ 9.98$

Variance

$\$ 99.57$

Skewness

0.2460

Kurtosis

2.82

Coeff. of Variability

0.1456

Minimum

$\$ 42.61$

Maximum

$\$ 110.17$

Range Width

$\$ 67.56$

Mean Std. Error

$\$ 0.10$

Figure 22. Electricity price, \$/MWhe-probability distribution and statistics. 
Summary:

Entire range is from 6.74 to 17.41

Base case is 10.14

After 10,000 trials, the std. error of the mean is 0.02

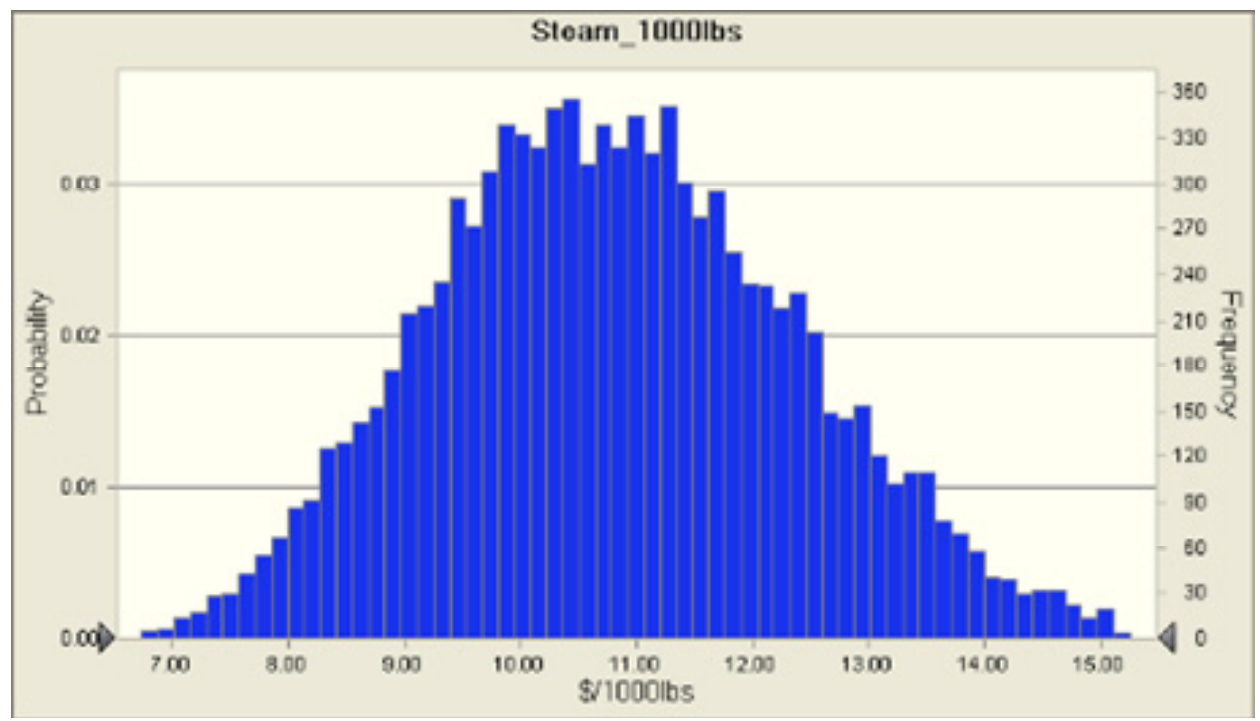

$\begin{array}{lr}\text { Statistics: } & \text { Forecast values } \\ \text { Trials } & 10,000 \\ \text { Mean } & 10.83 \\ \text { Median } & 10.76 \\ \text { Mode } & --- \\ \text { Standard Deviation } & 1.58 \\ \text { Variance } & 2.49 \\ \text { Skewness } & 0.2460 \\ \text { Kurtosis } & 2.82 \\ \text { Coeff. of Variability } & 0.1456 \\ \text { Minimum } & 6.74 \\ \text { Maximum } & 17.41 \\ \text { Range Width } & 10.68 \\ \text { Mean Std. Error } & 0.02\end{array}$

Figure 23. Steam price, $\$ / 1,000 \mathrm{lb}$-probability distribution and statistics. 


\section{PRELIMINARY SITE HAZARDS ASSESSMENT}

\subsection{Summary of Results}

An assessment was performed as part of the evaluation of the siting an HTGR cogeneration plant on the Waterford site to determine hazards and potential challenges that HTGR owners and HTGR designers need to be aware of when developing the HTGR design for the assumed co-location with the existing Waterford-3 nuclear plant on this site and nearby industrial facilities, and to evaluate the potential locations for the HTGR plant for suitability, considering certain Waterford site characteristics. The objectives of the site hazard assessments were to do an initial screening of representative locations in order to identify potential challenges and restraints to be addressed in design and licensing processes, evaluate potential HTGR locations on the Waterford site for potential hazards and describe some of the actions that may be necessary to mitigate impacts of hazards; and provide key insights that can inform the plant design process.

The report of this assessment ${ }^{5}$ presents a summary of the process methodology and the results of the assessment. The assessment considered health and safety, and other important siting characteristics to determine the potential impact of identified hazards and potential challenges presented by the location for this technology. The assessment was conducted based on the methodology for evaluating key characteristics of a site as presented in NGNP-LIC-ETR-RPT-0001, "Procedure for Site Hazards Evaluation and Impact Assessment."

Because the HTGR designs are still evolving in the early design phases, a great deal of specific information (i.e., key site parameters that bear on the design and site characteristics assumed in the design) was not available to support this assessment. However, some plant parameter envelope information from General Atomics for the Gas-Turbine, Modular Helium Reactor design was used in limited applications to support this assessment (e.g., bounding water use requirements, accident source term, and foundation embedment depth). The assessment collected the majority of information to inform HTGR designers on the hazards that might affect the licensing and operation of the HTGR from the Final Safety Analysis Report for Waterford-3.

This assessment concludes that the Waterford site appears to be viable for siting the HTGR plant. The assessment identified questions concerning technical and environmental factors that would require further evaluation if siting of a cogeneration plant were to be pursued prior to proceeding with formal site permitting and HTGR deployment. The more significant of the questions that could affect the HTGR plant design (technology or site geotechnical) and construction mitigation actions are:

- The proximity of a nearby railroad line to the site presents potential issues with respect to impacts from hazardous materials and security. Physical security considerations may create some specific needs for the design, and will require further evaluation, depending on the final location selected for siting the reactors and the surveillance technology selected.

- The site exhibits near surface groundwater conditions in soils that are prone to settlement when dewatered. This can create a risk of localized surface subsidence during the dewatering operations that would accompany construction and potentially operation of an HTGR facility.

- Equilibrated groundwater hydrodynamic pressures on the basemat (at approximately 160-ft deep) of the post-constructed HTGR facility must be considered in the HTGR facility design.

- Current and future planned flood protection and mitigation features in the vicinity of the site, such as levee systems, reservoirs, and diversion structures, which are maintained by the US Army Corps of Engineers, would need to be revalidated as applicable to adequate flood protection for newly installed HTGR modules at this site. 
All of these will require further evaluation during the design process but are judged to not disqualify this site for locating this HTGR plant.

The above summary listing does not include other challenges and potential hazards on or around the Waterford site, such as the bulk storage of hazardous substances at neighboring industrial facilities. Although these are important considerations for HTGR design and siting, they were not considered to be significant HTGR challenges. Similar issues have previously been successfully addressed at Waterford-3. Although requirements and acceptance criteria have been revised since the initial licensing of Waterford-3, it is judged that these issues can be successfully addressed and resolved under current regulation. While the evaluation in this report provides designers with preliminary insights they may have to address in the HTGR design should this or any site similar to this location be identified for siting a new nuclear plant, additional in-depth evaluations will be needed once a design is selected. These evaluations would include detailed site investigations in the hydrological, geological, and meteorological areas. Detailed evaluations will be needed to ensure physical security can be achieved, and additional detailed environmental and sociological investigations and permitting actions will be required.

\subsection{Interactive Considerations between HTGR and Waterford-3}

An assessment was also performed to identify impacts that the construction and operation of the HTGR facility may have on the existing Waterford-3 Nuclear Plant. The results of that assessment include a number of items, including the following examples that need to be evaluated further, but are judged based on this assessment to not disqualify this site for locating this HTGR plant:

- Effects of postulated HTGR radiological releases on the existing safety systems, technical specification requirements, and associated dose analyses

- The potential need to integrate the security and emergency planning functions for Waterford-3 and the HTGR facility

- Hazards or impacts to be considered during the HTGR facility's construction phase (site access/egress, excavation, wind-generated construction-related missiles, etc.).

\subsection{Other Considerations}

\subsubsection{Early Site Permit}

Pursuit of an ESP is optional but should be considered as a part of the project licensing approach for the HTGR facility because it can provide a relatively inexpensive vehicle for resolving site-related issues early in the licensing process. The licensing process for obtaining NRC approval of the ESP involves: performing a site characterization study and analysis of data for the chosen site location, completing a site safety analysis based on the selected design or a plant parameter envelop, and preparing and submitting an ESP report (license application). The ESP report is then reviewed by the NRC which may take 24 months. Public hearings are conducted prior to final approval of the ESP report. The overall process may take as long as $\sim 5$ years from when the process starts. 


\section{REFERENCES}

1. Public Law 109-58-AUG. 8, 2005, “Energy Policy Act of 2005,” U.S. Congress, 2005.

2. Nelson, L., A. Gribik, V. Maio, M. McKellar, M. Patterson, and R. Wood, Integration of High Temperature Gas-Cooled Reactors into Industrial Process Applications, INL/EXT-09-16942, Idaho National Laboratory, Revision 3, September 2011.

3. Nelson, L., A. Gandrik, M. McKellar, E. Robertson, M. Patterson, and R. Wood, Integration of High Temperature Gas-Cooled Reactors into Selected Industrial Process Applications, INL/EXT-1123008, Idaho National Laboratory, August 2011.

4. Idaho National Laboratory, High Temperature Gas-cooled Reactor Projected Markets and Preliminary Economics, INL/EXT-10-19037, Revision 1, August 2011

5. Idaho National Laboratory, NGNP Site 2, Hazards Assessment, INL/EXT-11-23178, September 2011.

6. General Atomics, Conceptual Design Report-Steam Cycle Modular Helium Reactor, (SC-MHR) Demonstration Plant, NGNP-R00016, December 2010.

7. TEV-1196, Assessment of High Temperature Gas Reactor (HTGR) Capital and Operating Costs, Idaho National Laboratory Technical Evaluation, April 2011

8. TEV-988, "Sensitivity of HTGR Heat and Power Production to Reactor Outlet Temperature, Economic Analysis,” Revision 1, Idaho National Laboratory, July 8, 2011. 